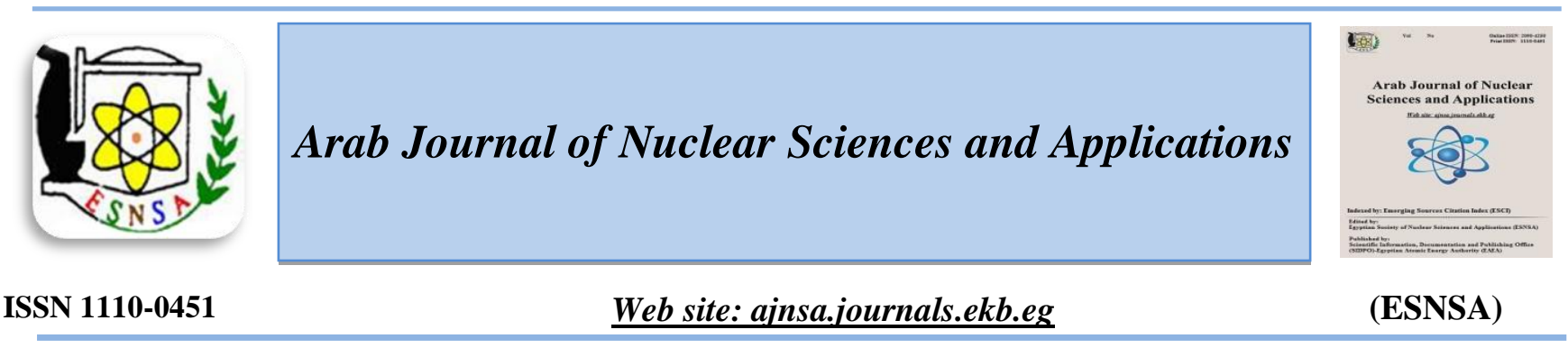

\title{
Preparation and Characterization of a Magnetic Nanocomposite Based on Gum Arabic/2-Hydroxyethylmethacrylate Using Gamma Irradiation for Use in Biomedical Application
}

\author{
Sh.M. Nasef ${ }^{1}$, N.A. Badawy ${ }^{2}$, F.H. Kamal ${ }^{2}$, S.F. Sherbiny ${ }^{2}$ and E.M. El-Nesr ${ }^{1}$ \\ ${ }^{1}$ Polymer Chemistry Department, National Center for Radiation Research and Technology, Atomic Energy Authority, \\ Cairo, Egypt. \\ ${ }^{2}$ Chemistry Department, Faculty of Science (Girls), Al-Azhar University, Cairo, Egypt.
}

\begin{abstract}
Received 4 ${ }^{\text {th }}$ Aug. 2018 Magnetic nanoparticles were prepared from gum Arabic (GA), 2-hydroxyethylmethacrylate (HEMA) Accepted $28^{\text {th }}$ Mar. 2019 copolymer hydrogel using gamma irradiation. Factors affecting the preparation of (GA/HEMA) copolymer hydrogel and the magnetic nanocomposite of (GA/HEMA)-( $\left.\mathrm{Fe}_{3} \mathrm{O}_{4}\right)$, such as irradiation dose, copolymer composition, copolymer concentration and magnetite concentration, were investigated. The swelling property of the prepared hydrogels was studied and the results showed that the swelling percent increases with increasing PH and reaches equilibrium swelling after $6 \mathrm{~h}$. The obtained hydrogel and its magnetic nanocomposites were characterized using Fourier Transform Infrared Spectroscopy (FTIR), thermogravimetric analysis (TGA), Scanning Electron Microscopy (SEM) and Transmission electron microscope (TEM). The presence of $\mathrm{Fe}_{3} \mathrm{O}_{4}$ inside the $\mathrm{GA} / \mathrm{HEMA}-\mathrm{Fe}_{3} \mathrm{O}_{4}$ nanocomposites was confirmed by X-ray diffraction (XRD) and energy dispersive X-ray spectroscopy (EDX). The magnetic properties were characterized by Vibrating sample magnetometer (VSM). Finally, the drug loading and in vitro release properties of the (GA/HEMA) copolymer hydrogel and its magnetic nanocomposites were also evaluated using endoxan as an anticancer drug model. The results showed that the optimum endoxan drug release was $97 \%$ from (GA/HEMA)-( $\left.\mathrm{Fe}_{3} \mathrm{O}_{4}\right)$ nanocomposite during $210 \mathrm{~min}$. It could be concluded that (GA/HEMA)-( $\left.\mathrm{Fe}_{3} \mathrm{O}_{4}\right)$ nanocomposite could be used for localized drug delivery for the endoxan drug in a neutral environment of the intestine.
\end{abstract}

Keywords: Gum Arabic / HEMA / Magnetite $\left(\mathrm{Fe}_{3} \mathrm{O}_{4}\right)$ / Nanocomposites / Gamma Irradiation / Endoxan, Drug Delivery

\section{Introduction}

Magnetic nanoparticles (MNPs) have received much attention over the past decade due to their biochemical and biomedical application. Magnetic nanoparticles have special relevance to biomedical applications due to their size compatibility with cells, viruses, proteins and genes. Their sizes are small enough to move inside the body without disrupting normal functions and can access spaces inaccessible by other materials. The advantages of using MNPs for such purposes are: 1) ease of preparation and non-toxicity; 2) small sizes and large surface areas; 3) facile chemical functionalization; 4) excellent biocompatibility and stability; 5) efficient drug conjugation, and 6) magnetic field. Such unique properties of MNPs

Corresponding author: Shaimaa.nasef@eaea.org.eg,

DOI: 10.21608/ajnsa.2019.4636.1106

(C) Scientific Information, Documentation and Publishing Office (SIDPO)-EAEA 
enabled their use as drug delivery vehicles to the desired site (e.g., tumor site) using an external magnetic field [1]. This approach is called magnetic drug targeting (MDT) and has emerged as a versatile technique to treat complex diseases. Magnetic nanoparticles fasters in the field of cancer treatments where hysteresis loses of magnetic nanoparticles generated during their cyclic remagnetization under applied alternating magnetic fields are exploited to destroy cancer cells and tissues. Cancer is a leading cause of death worldwide, and despite the availability of several treatment modalities, cancer therapy remains a great challenge. Chemotherapy is the main treatment modality for cancer patients. Cancer chemotherapy is usually obstructed mainly by low selectivity of the anticancer drugs towards the cancer cells, which causes severe side effects [2]. Thus, targeted drug delivery systems are preferred, which have been used to increase the efficiency of drug delivery to specific tissues as well as to decrease its side effects. Radiation technology is one such method, by which it is possible to synthesize nanoparticles, in situ the hydrogel matrix for possible uses in medical applications, where even small contamination is undesirable [3]. Poly(2-hydroxyethylmethacrylate), PHEMA is a favorable ebiomaterial because of its lack of toxicity, good blood compatibility, its inertness to normal biological process, which shows resistance to degradation [4]. Moreover, it is not absorbed by the body $[\mathbf{5}, \mathbf{6}]$, and its physicochemical properties are similar to those of living tissues [5]. Thus, it can be used in numerous applications such as drug delivery systems. Maximum swelling in water of PHEMA is thermodynamically limited to about $40 \%$. Therefore, in order to increase its swelling degree, HEMA has been copolymerized with a very hydrophilic polymer. On the other hand, gum Arabic (GA) is a water-soluble natural polysaccharide having a high solubility, $\mathrm{pH}$ stability, nontoxicity and has been used as a drug delivery vehicle not only to achieve sustained release, but also possibly to improve the bioavailability of some pharmaceutical agents [7]. Recently, the use of GA has been extended to the nanotechnology and nanomedicine fields, due to its biocompatibility for in vivo applications, as well as its stabilization of nanostructures. GA has been probed for the coating and increasing the biocompatibility of iron oxide magnetic nanoparticles [8]. Endoxan is an antineoplastic agent, prescribed for many types of cancers such as lymphatic cancer, cancer of white blood cells and plasma cells, etc. It slows down or stops the growth of cancer cells in the body. Dosage is about $(0.25 \mathrm{mg})$. The aim of the present work is to synthesize (GA/HEMA) copolymer hydrogel and (GA/HEMA)- $\left(\mathrm{Fe}_{3} \mathrm{O}_{4}\right)$ magnetic nanocomposites using gamma irradiation for targeted drug delivery system.

\section{Experimental}

\section{Materials}

Gum Arabic (GA) (Qualikems, India). 2hydroxyethylmethacrylate (HEMA) of purity $95 \%$ (Sigma-Aldrich Chemie GmbH., United Kingdom). Iron(III) Chloride anhydrous $\left(\mathrm{FeCl}_{3}\right)$ (BDH, England). Ferrous Chloride Hydrate $\left(\mathrm{FeCl}_{2} \cdot \mathrm{xH}_{2} \mathrm{O}\right)$ M.W: $126.75+\mathrm{aq}$ (LOBA, India). Sodium dihydrogen orthophosphate-I-hydrate (El Nasr Pharma Ceutical Chemicals Co.). Endoxan (Cyclophosphamide) drug (Baxter, GMBH, Germany). Other chemicals and solvents are used without further purification.

\section{Methods and Apparatus}

\section{a- Methods}

Synthesis of Gum Arabic (GA), 2 Hydroxyethylmethacrylate (HEMA) Copolymer Hydrogel by Gamma Irradiation

GA/HEMA copolymer hydrogel was prepared by dissolving separately at different ratios of (GA) and (HEMA) in distilled water. The GA, HEMA solutions were then well mixed with continuous stirring until complete miscibility was achieved. The ratios of GA and HEMA in the mixtures were (0/100), (20/80), (30/70) and (40/60) wt\% and at different total copolymer concentration of $(10,20$, 30,40 and $50 \mathrm{wt} \%$ ). The prepared solution was taken in several glass test tubes and irradiated at $(10,20,30,40$ and $50 \mathrm{kGy})$ using cobalt-60 gamma rays at a dose rate of $1.9 \mathrm{kGy} / \mathrm{h}$ Indian gamma cell. After copolymerization, test tubes were broken; the formed hydrogel cylinders were removed and cut into disks of $2 \mathrm{~mm}$ thickness and $5 \mathrm{~mm}$ diameter. The samples were then washed with excess water to remove the unreacted materials and dried at room temperature up to a constant weight.

\section{Preparation of magnetite $\left(\mathrm{Fe}_{3} \mathrm{O}_{4}\right)$}

Iron oxide magnetic nanoparticles were prepared on the basis of co-precipitation of $\mathrm{Fe}^{3+}$ and $\mathrm{Fe}^{2+}$ 
with a molar ratio of $2: 1$, according to this method, $1 \mathrm{gm}$ of $\mathrm{Fe}^{+2}$ and $2 \mathrm{gm}$ of $\mathrm{Fe}^{+3}$ were dissolved into $50 \mathrm{~mL}$ of distilled water. The mixture was stirred vigorously using a magnetic stirrer at $80^{\circ} \mathrm{C}$. The solution was bubbled with nitrogen gas $\left(\mathrm{N}_{2}\right)$ for $30 \mathrm{~min}$ to prevent unwanted oxidation. Then $2.5 \mathrm{M} \mathrm{NaOH}$ solution was dropped slowly into the mixture solution until the $\mathrm{pH}$ value 9 was attained. The reaction continued at that temperature for 1 hour under vigorous stirring on the magnetic stirrer, the precipitate was immediately produced. Consequently, the formation of $\mathrm{Fe}_{3} \mathrm{O}_{4}$ MNPs occurred with black precipitation. These particles were then separated from the solution and were then washed many times with distilled water to remove excess of sodium ions. Finally, the product was vacuum dried at $60-70^{\circ} \mathrm{C}$. After the drying process, the magnetic iron oxide $\left(\mathrm{Fe}_{3} \mathrm{O}_{4}\right)$ nanoparticles were ground for further use. The advantages of the coprecipitation method are high reproducibility of NPs and a large amount of magnetic NPs that can be produced per batch, however, difficulties in controlling the shape and size distribution of the NPs are well identified [9]. The possible reaction for the formation of $\left(\mathrm{Fe}_{3} \mathrm{O}_{4}\right)$ can be [10]:

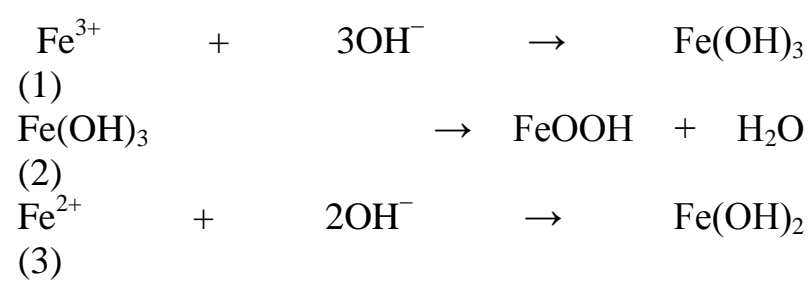

$2 \mathrm{FeOOH}+\mathrm{Fe}(\mathrm{OH})_{2} \rightarrow \mathrm{Fe}_{3} \mathrm{O}_{4} \downarrow+2 \mathrm{H}_{2} \mathrm{O}$

(4)

black ppt

Preparation of $\mathrm{GA} / \mathrm{HEMA} /\left(\mathrm{Fe}_{3} \mathrm{O}_{4}\right)$ nanocomposite by gamma irradiation

Different concentrations of prepared magnetite of known dry weights $(0.4,0.6,0.8,1,2$ and $3 \mathrm{wt} \%)$ were added into the GA/HEMA aqueous solution of composition (40:60) and total copolymer concentration $40 \mathrm{wt} \%$, the dispersions were occurred by placing solution in sonicated water bath for $5 \mathrm{~h}$. The prepared solution was taken in several glass test tubes and subjected to gamma rays at irradiation dose $30 \mathrm{kGy}$. The hydrogel cylinders were removed and cut into disks of $2 \mathrm{~mm}$ thickness and $5 \mathrm{~mm}$ diameter. The samples were then washed with excess water to remove the unreacted materials and dried at room temperature to arrive at a constant weight.

\section{Drug loading into the polymeric hydrogels and its magnetic nanocomposite}

The loading of the endoxan drug onto the prepared hydrogels and its magnetic nanocomposite was carried out by the soaking method. Certain weights of (GA/HEMA) copolymer hydrogel of copolymer composition (40:60), total copolymer concentration 40wt $\%$ and irradiation dose $30 \mathrm{kGy}$, and its magnetic nanocomposite of magnetite concentration $(0.4 \mathrm{wt} \%)$ were allowed to swell in the drug solution of different concentrations (50, $100,150,200$ and $250 \mathrm{ppm})$ at $37^{\circ} \mathrm{C}$ and $\mathrm{pH} 7.4$ for $24 \mathrm{~h}$ and then dried at room temperature.

The concentration of the solution was measured using UV/VIS spectrophotometer at a wavelength of $208 \mathrm{~nm}$. The amount of drug loaded was calculated as follows [11]:

$\mathrm{q}_{\mathrm{e}}=\left(\left(\mathrm{C}_{\mathrm{i}}-\mathrm{C}\right) / \mathrm{m}\right) \times \mathrm{V}_{\mathrm{t}}$

Where $\mathrm{q}_{\mathrm{e}}$ is the drug uptake in $(\mathrm{mg} / \mathrm{g}), \mathrm{C}_{\mathrm{i}}$ and $\mathrm{C}$ are the initial and equilibrium concentrations of drug solution $(\mathrm{mg} / \mathrm{ml}), \mathrm{V}_{\mathrm{t}}$ is the volume of solution $(\mathrm{ml})$, and $\mathrm{m}$ is the weight of dry hydrogel and nanocomposites $(\mathrm{g})$.

Drug release from the polymeric hydrogels and its magnetic nanocomposite

Release experiments were performed by placing the re-weighed hydrogel and its magnetic nanocomposite loaded with drug (at a concentration of $250 \mathrm{ppm})$ into Simulated Intestinal Fluid solutions (SIF) of $\mathrm{pH} 7.4$ and at $37^{\circ} \mathrm{C}$. SIF medium was prepared by adding $250 \mathrm{ml}$ of $0.2 \mathrm{M}$ potassium dihydrogen phosphate and 118 $\mathrm{ml}$ of $0.2 \mathrm{M}$ sodium hydroxide [12]. First, the loaded hydrogels and loaded magnetic nanocomposite were put in $10 \mathrm{ml}$ of SIF solution. At a predetermined time, one-milliliter sample was withdrawn on definite time intervals to follow the release process. The amount of drug released from copolymer hydrogel and magnetic nanocomposite was determined by using UV/VIS spectrophotometer at an identical drug absorbance wavelength of $208 \mathrm{~nm}$.

The percentage of drug released was calculated by dividing the amount of drug diffused into 
release medium by the total amount of drug loaded into the hydrogels and its nanoparticles [13].

$$
\text { Drug release }(\%)=\left(\mathrm{C} / \mathrm{C}_{\mathrm{i}}\right) \times 100
$$

Where $\mathrm{C}$ and $\mathrm{C}_{\mathrm{i}}$ are the drug release and drug uptake in $(\mathrm{mg} / \mathrm{g})$, respectively.

\section{Determination of gelation percent}

The prepared hydrogel and its magnetic nanocomposites were extracted with water at $60^{\circ} \mathrm{C}$ (water-solid extraction) for $24 \mathrm{~h}$ in order to remove the soluble components and then dried at room temperature to a constant weight. The gelation percent was then calculated as follows:-

$$
\text { Gelation }(\%)=\left(\mathrm{W}_{\mathrm{g}} / \mathrm{W}_{\mathrm{o}}\right) \times 100
$$

where $\mathrm{W}_{\mathrm{g}}$ is the weight of dry hydrogel after extraction and $\mathrm{W}_{\mathrm{o}}$ is the initial weight of the dry hydrogel.

\section{Swelling behavior}

The dried hydrogel and its magnetic nanocomposites were weighed $\left(\mathrm{W}_{\mathrm{o}}\right)$ and immersed in distilled water for different time intervals at room temperature until maximum swelling was reached. Then the hydrogel sample was weighed after removing excess water on the surface of the sample with a filter paper. The weight of swollen hydrogel was determined $\left(\mathrm{W}_{\mathrm{s}}\right)$. The equilibrium degree of swelling was determined according to the following equation:

$$
\text { Swelling }(\%)=\left(\left(\mathrm{W}_{\mathrm{s}}-\mathrm{W}_{\mathrm{o}}\right) / \mathrm{W}_{\mathrm{o}}\right) \times 100
$$

Where $\mathrm{W}_{\mathrm{s}}$ and $\mathrm{W}_{\mathrm{o}}$ are the weights of swelled hydrogel and dry hydrogel, respectively.

\section{b- Apparatus}

i. Fourier-transform infrared spectroscopic analysis (FTIR)

The infrared spectra of (GA/HEMA) copolymer hydrogel and its magnetic nanocomposites were performed using an FT-IR spectrometer (Bruker, Unicom, Germany in the range of $\left.400-4000 \mathrm{~cm}^{-1}\right)$.

\section{ii. Scanning Electron Microscope (SEM)}

The surface morphology of (GA/HEMA) copolymer hydrogel and its magnetic nanocomposites were examined by the SEM technique. The micrographs were taken with a
JSM-5400 instrument from Joel (Japan) at a voltage of $30 \mathrm{kV}$.

\section{iii. Transmission electron microscope (TEM)}

Transmission electron microscopy (TEM) measurements of (GA/HEMA) copolymer hydrogel and its magnetic nanocomposites were performed with a (JEOL, JEM 100CX, electron microscopes, Japan) operating at $80 \mathrm{kV}$. To image the magnetite nanocomposites on TEM, finely grounded hydrogels nanocomposites samples were dispersed in $1 \mathrm{ml}$ of ethanol followed by sonication to get a solution of magnetite nanoparticles. Approximately $10-20 \mu \mathrm{l}$ of this solution was dropped on a $3 \mathrm{~mm}$ copper grid, drying at room temperature. The copper grid was inserted into a transmission electron microscope.

\section{iv. X-Ray diffraction (XRD) analysis}

$X$-ray diffraction measurements of (GA/HEMA) copolymer hydrogel and its magnetic nanocomposites were obtained with an XD-DI Series apparatus (Shimadzu 6000, Japan), using nickel-filtered and $\mathrm{Cu}-\mathrm{K}$ target. The XRD runs were carried out over the $2 \theta$ range from $4^{\circ}$ to $90^{\circ}$ at a scan speed of $8^{\circ} / \mathrm{min}, 30 \mathrm{ml} \mathrm{A}$ and voltage $40 \mathrm{kV}$. The average particle size of $\mathrm{Fe}_{3} \mathrm{O}_{4}$-NPs in the copolymer can be calculated using Scherrer's Equation [14]:

$$
\mathrm{L}=\mathrm{K} \lambda / \beta \cos \theta
$$

where $\mathrm{L}$ is the crystallite size $(\mathrm{nm}), \mathrm{K}$ is the Scherrer's constant with value of about 0.94 , where $\lambda$ the X-ray wavelength (1.5406 $\AA$ ), $\beta$ is the full width of the peak at half of the maximum intensity (rad) (FWHM) and $\theta$ is the diffraction angle corresponding to the maximum intensity peak in the XRD pattern.

\section{v. Thermogravimetric analysis (TGA)}

The TGA thermograms of (GA/HEMA) copolymer hydrogel and its magnetic nanocomposites were performed on a Shimadzu50 instrument (Kyoto, Japan) at a heating rate of $10^{\circ} \mathrm{C} / \mathrm{min}$ under flowing nitrogen $(20 \mathrm{ml} / \mathrm{min})$ from room temperature to $500^{\circ} \mathrm{C}$.

\section{vi. Energy-dispersive $x$-ray $(E D X)$ studies}

Energy-dispersive $\mathrm{X}$-ray was used to determine elemental constituents of prepared (GA/HEMA) copolymer hydrogel and its magnetic 
nanocomposites using Philips, Netherlands ESEM EDAX XL-30 instruments.

\section{vii. Vibrating-sample magnetometry analysis} (VSM)

The vibrating sample magnetometer of the $\mathrm{GA} / \mathrm{HEMA} /\left(\mathrm{Fe}_{3} \mathrm{O}_{4}\right)$ magnetic nanocomposites were measured at the National Research Centre (NRC), Cairo using VSM lake shore Model 7410 the USA, Digital Measurement System, Inc... The magnetic properties of nanocomposites were studied in the fields up to 31.5 Kilo Oersted (kOe).

\section{viii. UV-Vis spectrophotometer}

UV/VIS spectrometer model UV-Analytic Jena AG, German, at the wavelength of $208 \mathrm{~nm}$.

\section{Results and Discussion}

1-Factors affecting the gelation percent of (GA/HEMA) copolymer hydrogel

Radiation copolymerization reaction of polymers in aqueous solution utilizing gamma rays would result in a crosslinked network structure (gel-like materials). The radiation crosslinking can be easily adjusted by controlling the copolymer composition, copolymer concentration as well as irradiation dose [15].

a- Effect of copolymer composition

The gelation percent of (GA/HEMA) copolymer hydrogel as a function of copolymer composition is shown in Fig. (1). The results show that the gelation percent of the obtained (GA/HEMA) copolymer hydrogels is dependent on the copolymer composition. The use of copolymer fodder solution opulent with HEMA resulted in a higher gelation percent as compared to that prepared by using GA-opulent copolymer fodder solution. The increase in the GA content in the copolymer fodder solution reduced the gelation percent to reach about $95 \%$, at $40 \mathrm{wt} \%$ of GA concentration. Any further increase in the GA content leads to the prevention of the gelation process, and no gel is formed at all. This is due to the increase in the viscosity of reaction medium and thus restricting the movement of the free radical to reach the active sites on the polymeric substrate, so the lower degree of gelation was obtained [16]. This result is in coincidence with those reported by Mervat et al. [17] who investigated the increase of the monomer concentration increased the percent of gelation in gum Arabic hydrogels. This result suggested that the presence of HEMA with GA enhanced the gelation process of the copolymers due to the difference in the diffusion coefficient of both polymers. In addition, the acceleration of gelation is highly depended on HEMA concentration because the structure of HEMA includes a conjugated double bond $(-\mathrm{C}=\mathrm{C}-$ groups $)$ make the conjugated effect and polarity of HEMA is larger than that of GA [18]. This contradiction enables the HEMA and GA to copolymerize alternately. Moreover, HEMA has a higher sensitivity towards ionizing radiation than that of GA. Thus under ionizing radiation, simultaneous crosslinking of synthetic monomer, degradation of polysaccharides and grafting of monomer to polymer chains occurs leading to the formation of hydrogel [19].

\section{$b$ - Effect of copolymer concentration}

The copolymer concentration has a considerable role during gel preparation by radiation copolymerization method. Figure (2) shows the effect of copolymer fodder solution on the gelation percent of (GA/HEMA) copolymer hydrogel. The results show that, as the copolymer concentration increases, the gelation percent increases. At high copolymer concentration, a great number of molecules are available to react with the free radical on the backbone of the polymer chain. This increase is also due to the increase in the diffusion rate of the copolymer into the bulk of the substrate. In addition, the possibility of $\mathrm{H}$-abstraction via chain transfer would increase the production of a large number of growing chains giving rise to the substrate macroradicals. Thus the extent of chain propagation will be increased resulting in a greater degree of gelation add on [15]. At copolymer concentration higher than $50 \mathrm{wt} \%$, the reaction is not completed due to the high viscosity of the polymer.

\section{c- Effect of irradiation dose}

A polymer may be cross-linked or degrade on irradiation, depending on its chemical structure. HEMA is known to be a cross-linking polymer, while GA is a water-soluble natural polysaccharide that degrades upon irradiation by the breakdown of the main chains [20]. Thus, when HEMA is crosslinked, the degradation of GA also takes place in the reaction medium, and the overall manner of the reaction will depend on the relative concentrations 
of the two polymers [21]. The effect of irradiation dose on the gelation percent of (GA/HEMA) copolymer hydrogel is shown in Fig. (3). From this figure, it can be found that the gelation percent of (GA/HEMA) copolymer hydrogel increases with the increase of the dose up to $40 \mathrm{kGy}$ and then tends to decrease at a higher absorbed dose. When an aqueous solution of GA/HEMA at copolymer composition (40:60) is subjected to gamma irradiation, free radicals are generated. These radicals react randomly leading to the formation of a copolymer of GA and HEMA. However, when the absorbed dose reached a critical absorbed dose (gelation dose), the intermolecular recombination of free radicals readily occurred leading to the form a three-dimensional network. In addition, any increase in the absorbed dose would cause increased cross-linking density. At a sufficient high absorbed dose, the intramolecular free radical recombination resorted to dominate over the intermolecular radical recombination, which would terminate the crosslinking and begin to degrade the network. In other words, the rate of radiation degradation may be faster than the rate of radiation crosslinking. Therefore, the gelation percent was decreased.

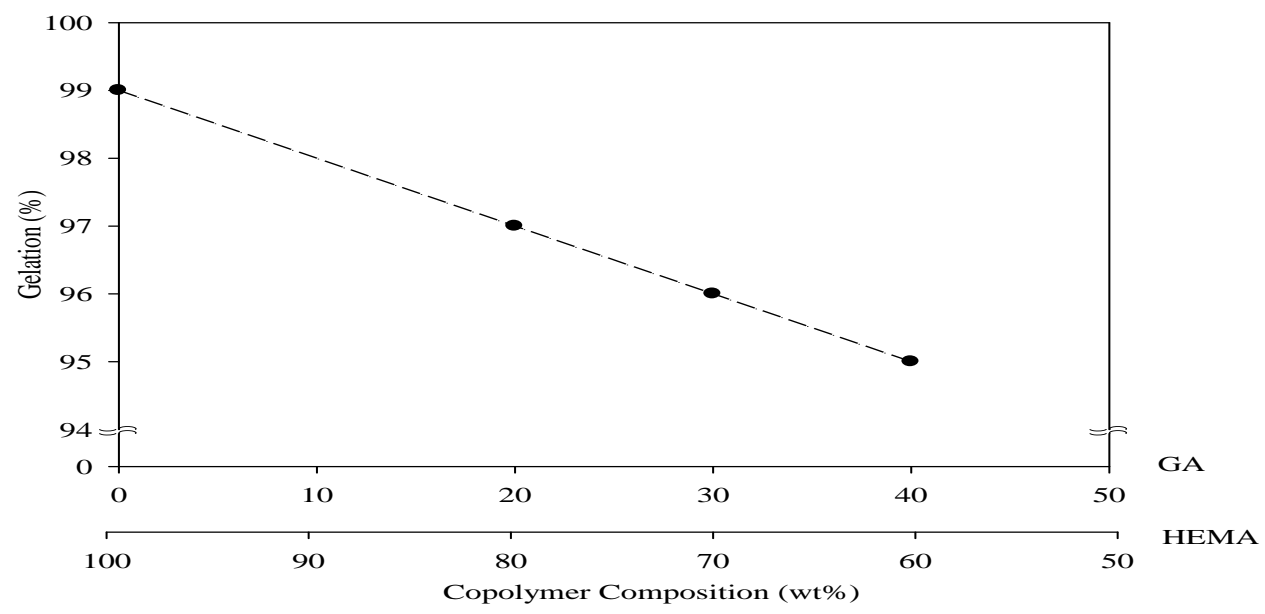

Fig. (1): Effect of copolymer composition on the gelation (\%) of (GA/HEMA) copolymer hydrogel at irradiation dose $30 \mathrm{kGy}$ and copolymer concentration $40 \mathrm{wt} \%$ in distilled water

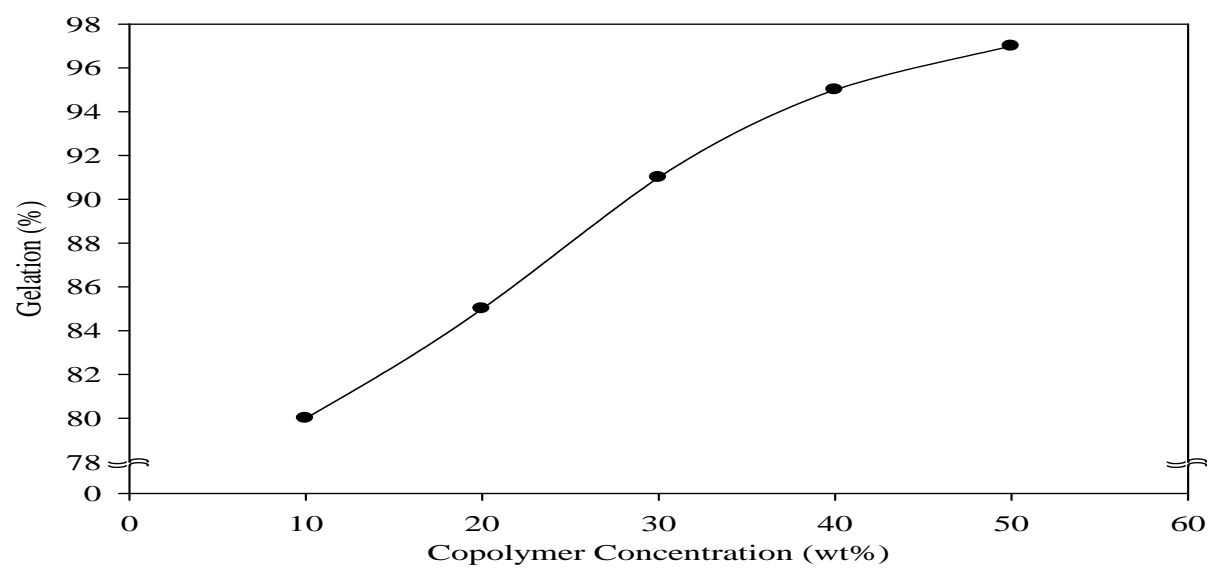

Fig. (2): Effect of copolymer concentration on the gelation (\%) of (GA/HEMA) copolymer hydrogel at copolymer composition (40:60) and irradiation dose $30 \mathrm{kGy}$ in distilled water 


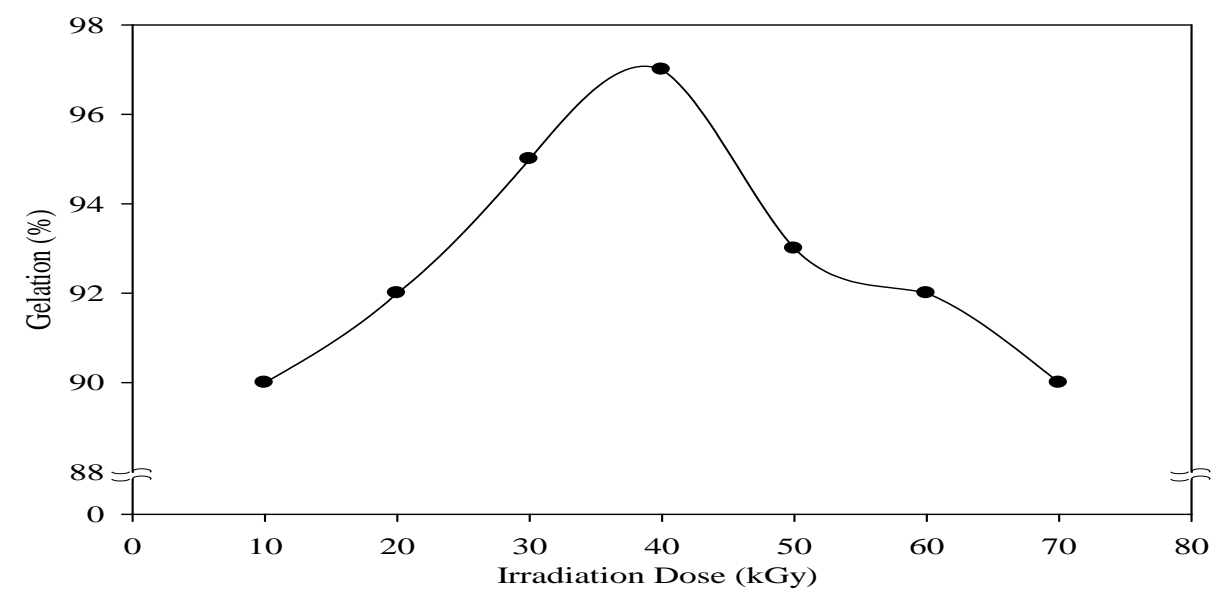

Fig. (3): Effect of irradiation dose on the gelation (\%) of (GA/HEMA) copolymer hydrogel at copolymer composition (40:60) and copolymer concentration $40 \mathrm{wt} \%$ in distilled water

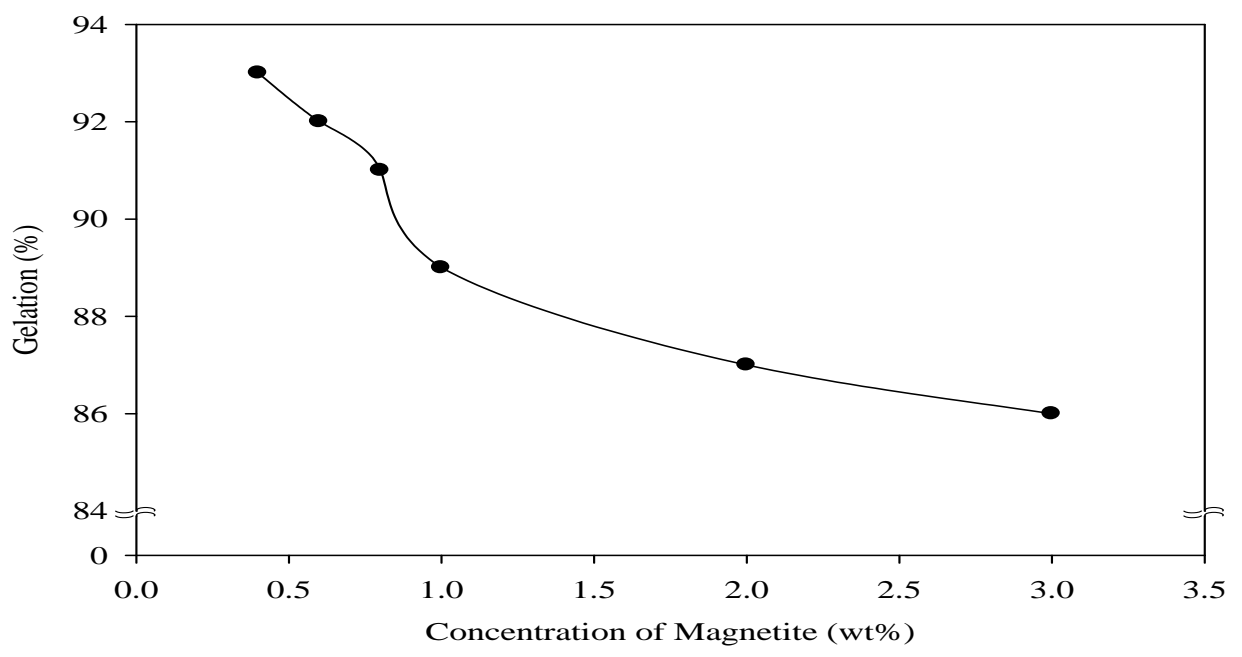

Fig. (4): Effect of $\left(\mathrm{Fe}_{3} \mathrm{O}_{4}\right)$ concentration on the gelation (\%) of (GA/HEMA) copolymer hydrogel of copolymer composition (40:60) at irradiation dose $30 \mathrm{kGy}$ and copolymer concentration $40 \mathrm{wt} \%$ in distilled water 


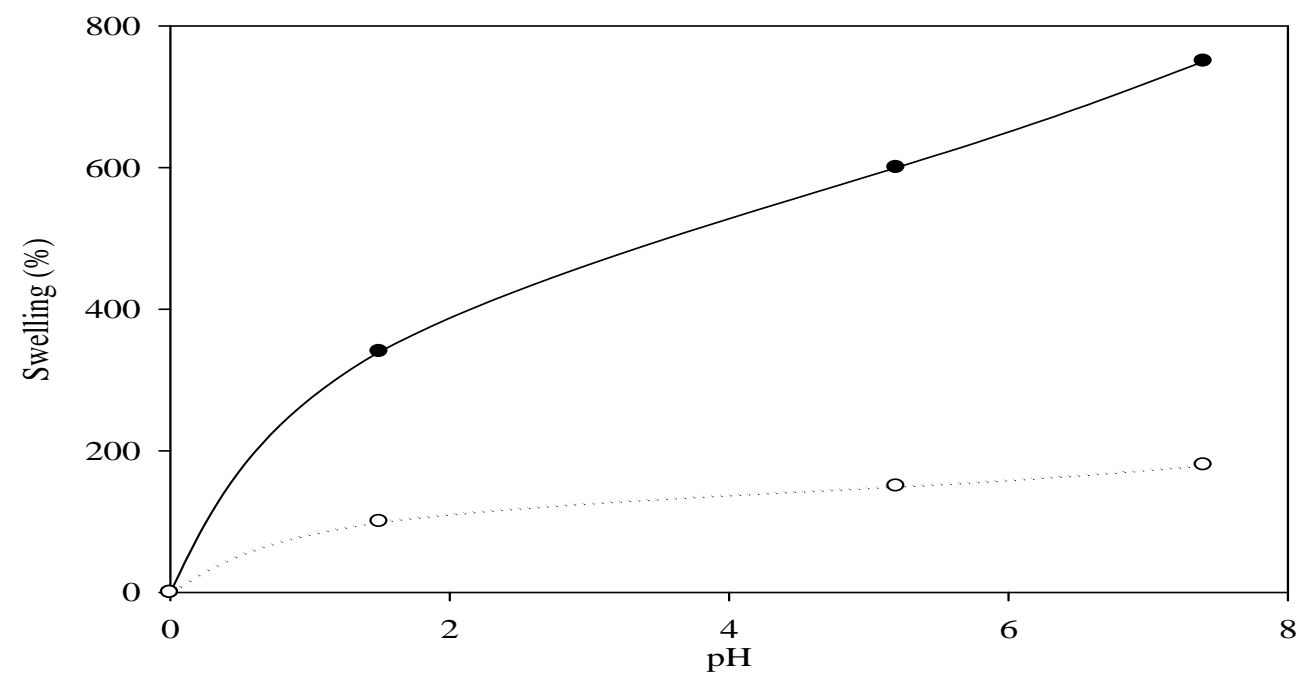

Fig. (5): Effect of $\mathrm{pH}$ on the swelling (\%) of (०) (GA/HEMA) copolymer hydrogel and (•) (GA/HEMA)-( $\left.\mathrm{Fe}_{3} \mathrm{O}_{4}\right)$ nanocomposite of concentration $(0.4 \mathrm{wt} \%)$, swelling time $24 \mathrm{~h}$

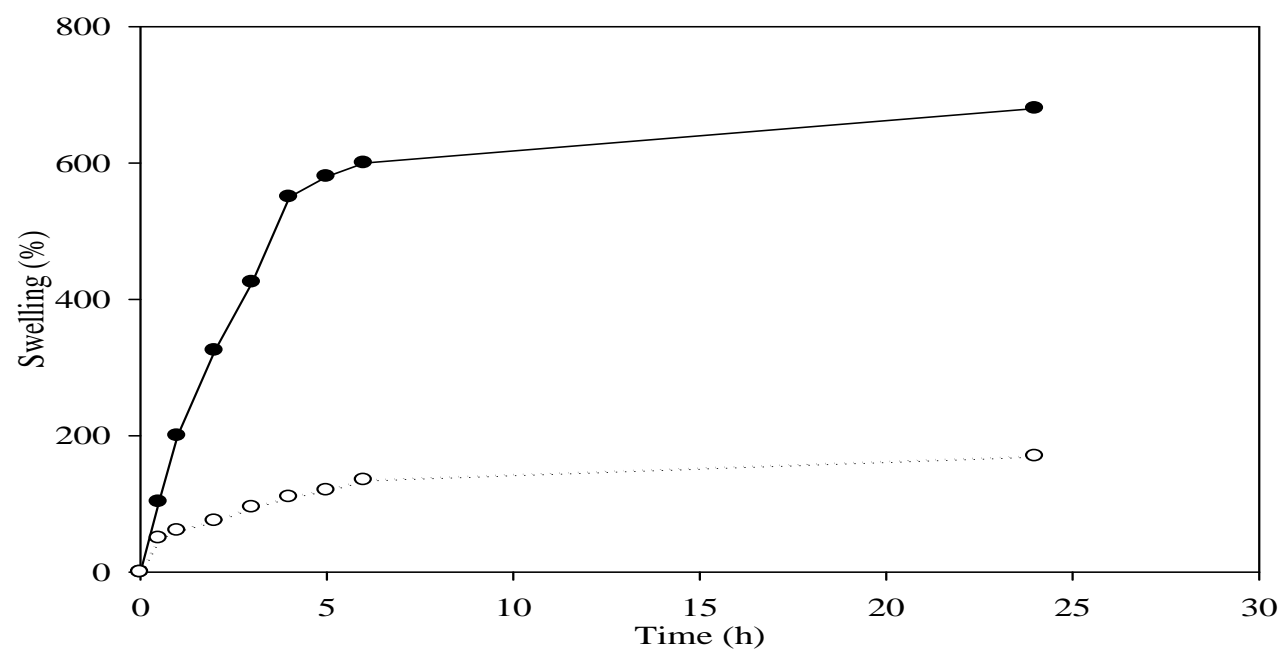

Fig. (6): Effect of soaking time on the swelling (\%) of (०) (GA/HEMA) copolymer hydrogel and $(\bullet)\left(\mathrm{GA} / \mathrm{HEMA}^{-}\left(\mathrm{Fe}_{3} \mathrm{O}_{4}\right)\right.$ nanocomposite of concentration $(0.4 \mathrm{wt} \%)$ at $\mathrm{pH} 7.4$ 


\section{Fourier-transform infrared spectroscopic analysis (FT IR) \\ FT-IR spectroscopy was used to determine the} functional groups in the hydrogels. Figure (7) shows the infrared spectra for blank GA, (GA/HEMA) copolymer hydrogel and (GA/HEMA)- $\left(\mathrm{Fe}_{3} \mathrm{O}_{4}\right)$ nanocomposites. As shown in Fig.7(a), it is obvious that GA gives a typical broad band at $3200-3500 \mathrm{~cm}^{-1}$ corresponding to $\mathrm{OH}$ stretching and band appears at $2900 \mathrm{~cm}^{-1}$ corresponding to $\mathrm{C}-\mathrm{H}$ stretching, another absorption band appears at $1592 \mathrm{~cm}^{-1}$ corresponding to $\mathrm{C}=\mathrm{O}$ stretching [26] and 1017 $\mathrm{cm}^{-1}$ corresponding to $\mathrm{C}-\mathrm{O}$ stretching and $\mathrm{N}-\mathrm{H}$ bending two bands at $1411 \mathrm{~cm}^{-1}$. Figure 7(b) shows, in the spectrum of (GA/HEMA) copolymer hydrogel, the additional sharp band at $1724 \mathrm{~cm}^{-1}$ corresponding to the ester group present in PHEMA [23, 27]. The other observed band at $1261 \mathrm{~cm}^{-1}$ corresponds to $\mathrm{CO}$ stretching vibration [10], the bands at 1162,1080 and $1019 \mathrm{~cm}^{-1}$ corresponding to C-O-C stretching also confirmed the presence of the ester group [27]. The absorption band at $939 \mathrm{~cm}^{-1}$ is assigned to $\mathrm{C}-\mathrm{N}$ group [28]. The bands in the range $845-617 \mathrm{~cm}^{-1}$ are due to the vinyl group [14]. The most distinct band in the spectra of the polymer networks was the absorption band of the carbonyl group $(\mathrm{C}=\mathrm{O})$ and the absorption band due to the $\mathrm{O}-\mathrm{H}$ groups. These bands contained information about the polymer complexes formed by a hydrogen bond and electrostatic interactions. Figure 7(c) shows the vibration absorption band for $\mathrm{Fe}-\mathrm{O}$ bond of $\mathrm{Fe}_{3} \mathrm{O}_{4}$ nanoparticles at $610 \mathrm{~cm}^{-1}[\mathbf{1 0}, \mathbf{2 9}, \mathbf{3 0}]$ which confirms the presence of iron oxide nanoparticles in the hydrogel networks. In (GA/HEMA)- $\left(\mathrm{Fe}_{3} \mathrm{O}_{4}\right)$ nanocomposites the characteristic bands for both HEMA and GA were present with a small shifting of position. Moreover, the O-H stretching band of (GA/HEMA)- $\left(\mathrm{Fe}_{3} \mathrm{O}_{4}\right)$ nanocomposites had a lesser intensity than (GA/HEMA) copolymer hydrogel which implies that the interaction between $\mathrm{Fe}$ nanoparticles and carboxylic groups existed [23]. Thus, FTIR spectroscopy confirms the mode of binding of $\mathrm{Fe}$ atoms within the polymer matrix.

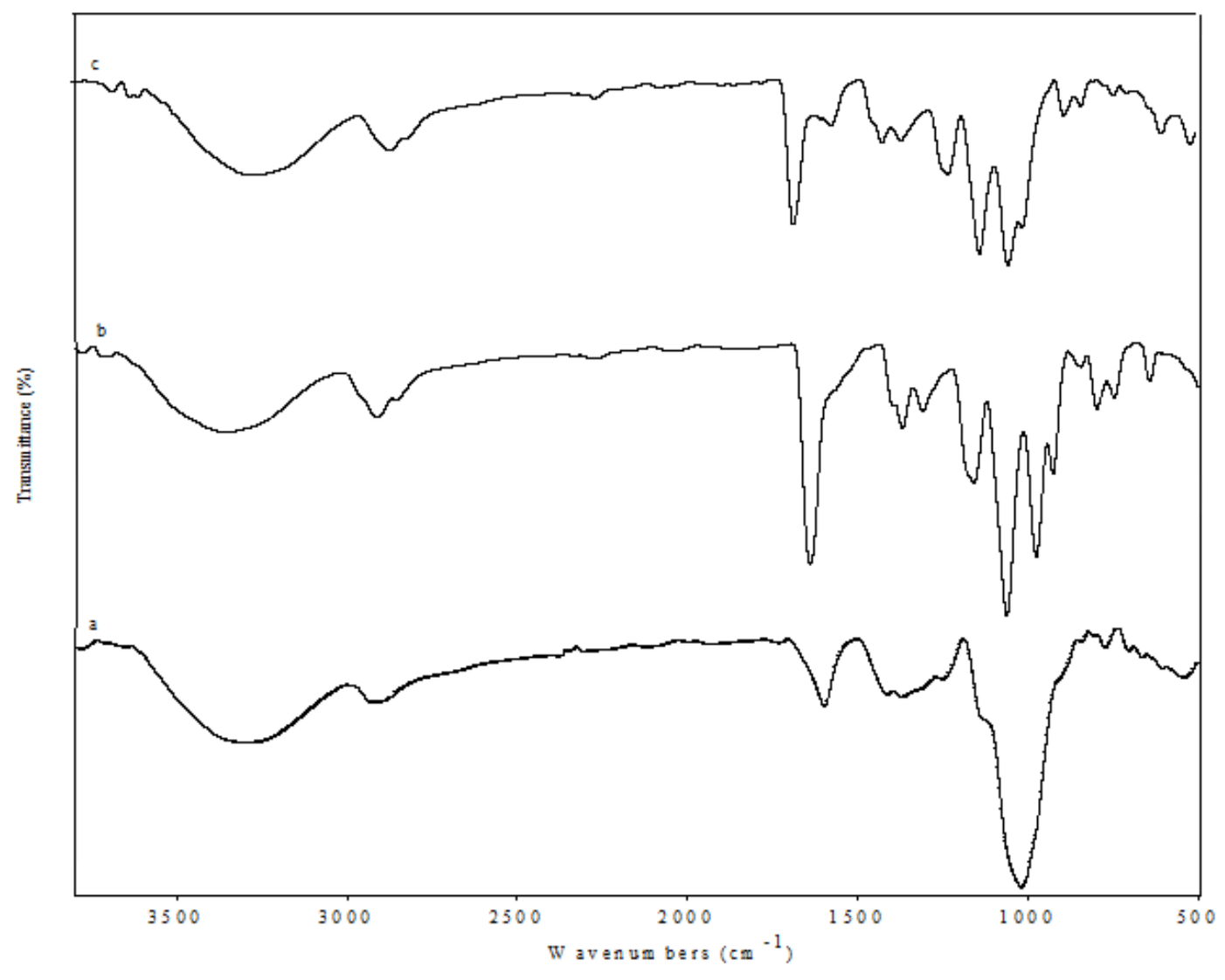

Fig. (7): FTIR spectra for (a) GA powder (b) (GA/HEMA) copolymer hydrogel of gelation percent (96\%) and (c) (GA/HEMA)$\left(\mathrm{Fe}_{3} \mathrm{O}_{4}\right)$ nanocomposite of concentration $(0.4 \mathrm{wt} \%)$ 


\section{X-ray diffraction (XRD) measurements}

$\mathrm{X}$-ray diffraction analysis is used to determine the crystallinity of the polymeric hydrogel. Figure (8) shows the XRD pattern of ferric chloride, ferrous chloride and $\left(\mathrm{Fe}_{3} \mathrm{O}_{4}\right)$. Figure 8 (a) shows characteristic diffraction peaks at $2 \theta=15^{\circ}, 17^{\circ}$, $19^{\circ}, 30^{\circ}, 33^{\circ}$ and $43^{\circ}$ which are attributed to ferric chloride powder. Figure 8(b) shows characteristic diffraction peaks at $2 \theta=16^{\circ}, 20^{\circ}, 22^{\circ}, 26^{\circ}, 30^{\circ}$, $32^{\circ}, 40^{\circ}, 42^{\circ}$ and $52^{\circ}$ which are attributed to ferrous chloride powder. The XRD pattern of $\left(\mathrm{Fe}_{3} \mathrm{O}_{4}\right)$ Fig.8(c), shows characteristic diffraction peaks at $2 \theta=30^{\circ}, 35^{\circ}, 43^{\circ}, 57^{\circ}$, and $62^{\circ}$. The positions and relative intensities of the reflection peaks of $\left(\mathrm{Fe}_{3} \mathrm{O}_{4}\right)$ agree with the XRD diffraction peaks of standard $\mathrm{Fe}_{3} \mathrm{O}_{4}$ samples [31].

The analysis revealed that the $\mathrm{Fe}_{3} \mathrm{O}_{4}$ was successfully prepared from ferric chloride and ferrous chloride via in situ coprecipitation method. Figure (9) shows the XRD pattern of (GA/HEMA) copolymer hydrogels of gelation percent $(96 \%)$, (GA/HEMA)-( $\left.\mathrm{Fe}_{3} \mathrm{O}_{4}\right)$ nanocomposite of concentration $(0.4,1) \mathrm{wt} \%$. The XRD pattern of (GA/HEMA) copolymer hydrogel Fig. 9 (a) shows a strong diffraction peak at $2 \theta=20^{\circ}$ that confirms the crystalline nature of the gum Arabic [32]. The XRD of nanocomposite with different amounts of $\left(\mathrm{Fe}_{3} \mathrm{O}_{4}\right)$ Fig. 9 (b, c) shows the corresponding peak of GA besides three new diffraction peaks at $2 \theta=$ $30^{\circ}, 33^{\circ}, 43^{\circ}$ which referred to the existence of a nanocrystalline spinel phase due to $\left(\mathrm{Fe}_{3} \mathrm{O}_{4}\right)$ encapsulated in copolymer hydrogel network. The disappearance of $57^{\circ}$ and $62^{\circ}$ peaks in the diffraction pattern of the nanocomposite is due to covering of $\left(\mathrm{Fe}_{3} \mathrm{O}_{4}\right)$ crystallite by crystalline polymer [10]. It has also been observed that the intensity of $\left(\mathrm{Fe}_{3} \mathrm{O}_{4}\right)$ peaks has decreased, during its presence in the nanocomposite which is an indication of incorporation within pores of the hydrogel network [33]. It is also noted that a phase change of $\left(\mathrm{Fe}_{3} \mathrm{O}_{4}\right)$ did not occur because peaks were not shifted for other $2 \theta$ reflections and this is favorable for maintaining the magnetic properties of the nanocomposites. On the other hand, with the increasing amounts of $\left(\mathrm{Fe}_{3} \mathrm{O}_{4}\right)$, the intensity of the typical reflection peaks of $\mathrm{Fe}_{3} \mathrm{O}_{4}$ was increased. GA/HEMA copolymer hydrogel appeared crystallinity of GA, while nanocomposites revered a crystalline structure which was referred to magnetite crystallized phases. According to the Scherrer's equation, the average particle size of the iron nanoparticles in the (GA/HEMA)- $\left(\mathrm{Fe}_{3} \mathrm{O}_{4}\right)$ nanocomposite with different contents are 18 and $28.65 \mathrm{~nm}$ for concentrations 0.4 and $1 \mathrm{wt} \%$, respectively, which is basically in accordance with the transmission electron microscopy. From the Scherrer's equation, the crystallite size of $\mathrm{Fe}_{3} \mathrm{O}_{4^{-}}$ NPs increases by increasing the metal contents in the polymer.

\section{Thermal gravimetric analysis (TGA)}

TGA is useful in obtaining enough information about polymer relative thermal stability. The thermal behavior of the prepared (GA/HEMA) copolymer hydrogel of $(96 \%)$ gelation (GA/HEMA)-( $\left.\mathrm{Fe}_{3} \mathrm{O}_{4}\right)$ nanocomposites of concentration $(0.4,1) \mathrm{wt} \%$ were measured from ambient temperature up to $500^{\circ} \mathrm{C}$. Figure 10 (a) shows the thermogram of (GA/HEMA) copolymer hydrogel, which indicates that the weight remains at certain temperatures ranging from ambient to $500^{\circ} \mathrm{C}$. The thermogram shows three decomposition stages; the first decomposition stage shows a weight loss of $5 \mathrm{wt} \%$, within a temperature below $200^{\circ} \mathrm{C}$. This weight loss corresponds to the evaporation of water. The major weight loss occurs in the second decomposition step in the range of $\left(200-380^{\circ} \mathrm{C}\right)$, and is due to decomposition of GA [34] (decomposition of side groups and branches of the hydrogels). During the third decomposition stage beyond $400^{\circ} \mathrm{C}$, the weight loss is attributed to the main-chain scission of polymer and matrices which result in rapid decomposition into carbon dioxide and volatile hydrocarbons [18]. The high residue content, up to $4 \mathrm{wt} \%$, at $500^{\circ} \mathrm{C}$ is observed in thermogram for the (GA/HEMA) copolymer hydrogels of (96\%) gelation. From the TGA curve, it is clear that the thermal stability of (GA/HEMA)- $\left(\mathrm{Fe}_{3} \mathrm{O}_{4}\right)$ nanocomposites is improved when compared with (GA/HEMA) copolymer hydrogels. This is due to two main reasons. The first reason for this change is the Fe NPs have higher thermal stability than the polymeric chains of the hydrogel. So, the presence of these nanoparticles in the reaction medium makes it thermally more stable. The second reason is the reduced mobility of the polymeric chains on loading of iron nanoparticles, leading to improved thermal stability. The results of the FT-IR study indicate that the iron nanoparticles can react with the existing groups in the polymeric chains. Such interactions can lead to the formation of several weak intermolecular cross-links between the polymeric chains, and therefore their mobility was 
restricted [35]. Thus, the degradation reaction will be slowed down, and the decomposition occurred at a higher temperature in the presence of Fe NPs. As can be seen from Fig. (10), it is found that the initial degradation temperature of copolymer hydrogels was higher than that of nanocomposites due to the catalytic property of the $\mathrm{Fe}_{3} \mathrm{O}_{4}$ nanoparticles [36, 37 and 38]. The high residue content, up to 9 and $15 \mathrm{wt} \%$ at $500^{\circ} \mathrm{C}$ observed in thermogram for concentration $(0.4,1) \mathrm{wt} \%$, respectively indicates that (GA/HEMA)- $\left(\mathrm{Fe}_{3} \mathrm{O}_{4}\right)$ nanocomposites have significantly higher thermal stability than that of (GA/HEMA) copolymer hydrogels, which is suitable for practical uses. These studies indicated the improvement of stability of (GA/HEMA)-( $\left.\mathrm{Fe}_{3} \mathrm{O}_{4}\right)$ nanocomposites, due to of iron particle has the "nano-effect" whose formed inside the template [23]

\section{Scanning electron microscope}

Figure (11) shows the SEM images of (GA/HEMA) copolymer hydrogel in comparison with $\mathrm{GA} / \mathrm{HEMA} / \mathrm{Fe}_{3} \mathrm{O}_{4}$ magnetic nanocomposites. It can be noticed that (GA/HEMA) copolymer hydrogel possesses wide hollow pore size at higher magnifications indicating that water molecules can be accommodated and easily diffused in and out. While SEM images of (GA/HEMA)- $\left(\mathrm{Fe}_{3} \mathrm{O}_{4}\right)$ nanocomposites show the presence of magnetic nanoparticles as irregular spherical shapes over all the surface of the hydrogels and also embedded in the polymer matrix of GA/HEMA [39].
Transmission electron microscope (TEM)

The size of the magnetic nanoparticles in the prepared hydrogels was determined using a transmission electron microscope. Figure 12 (a) represents the TEM image of (GA/HEMA) copolymer hydrogel of $(96 \%)$ gelation. The TEM analysis demonstrated that the magnetic nanoparticles were not sprinkled in the polymer matrix. On the other hand, Fig. $12(b, c)$ shows the TEM image of (GA/HEMA)- $\left(\mathrm{Fe}_{3} \mathrm{O}_{4}\right)$ nanocomposites at concentrations $(0.4,1)$ wt $\%$ which facilitates dispersion of nanoparticle throughout the network structure due to carboxyl and hydroxyl groups of the polymeric chains [23]. The results indicate that the metal means size in (GA/HEMA)-( $\left.\mathrm{Fe}_{3} \mathrm{O}_{4}\right)$ nanocomposites at concentrations $(0.4,1) \mathrm{wt} \%$ equal 20.1 and 30.3 $\mathrm{nm}$, with average ranges of 10.5-34.1 and 20.4-47 $\mathrm{nm}$, respectively. The formation of small nanoparticles may help the incorporation of $\left(\mathrm{Fe}_{3} \mathrm{O}_{4}\right)$ nanoparticles within (GA/HEMA) polymeric matrices as also indicated by XRD measurements. It is also noticed that the particle size was increased by increasing the metal contents in the polymer due to the crosslinking effect and the difference in the number of effective chains which affect the penetration and control the rate of iron nanoparticles formation $[\mathbf{4 0 , 4 1 ]}$.

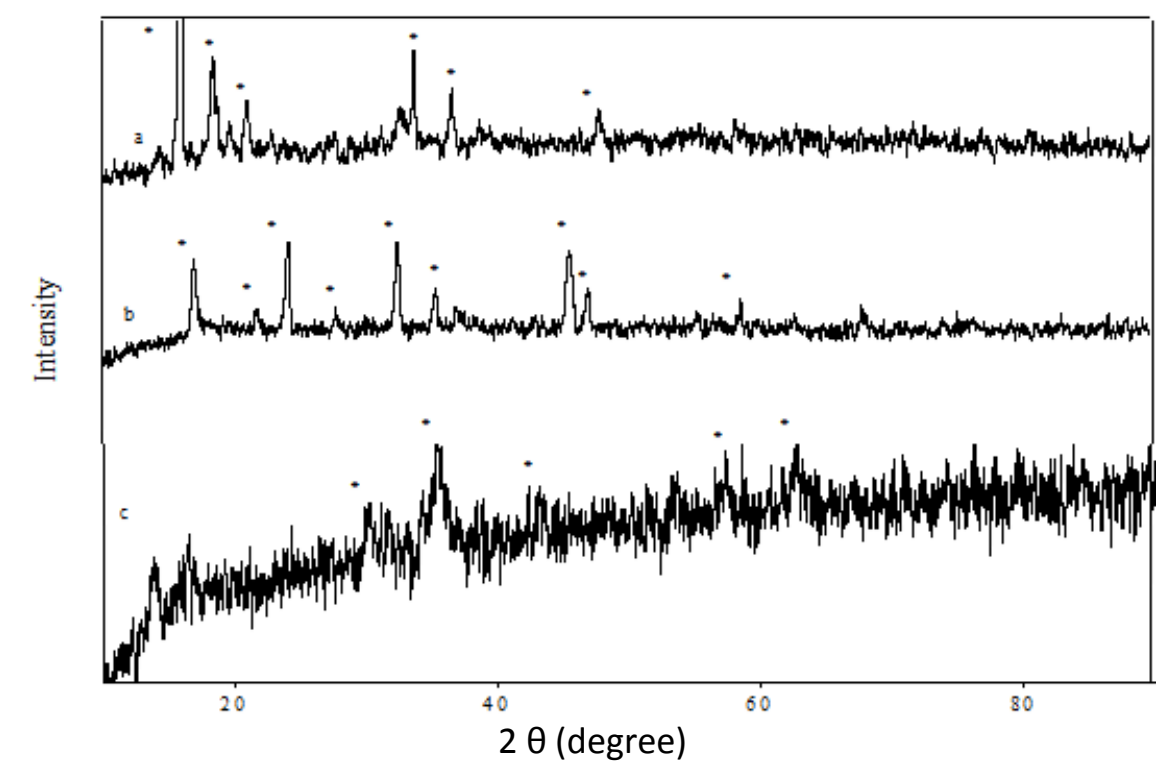

Fig. (8): XRD diffraction patterns of (a) ferric chloride, (b) ferrous chloride and (c) (Fe3O4). 


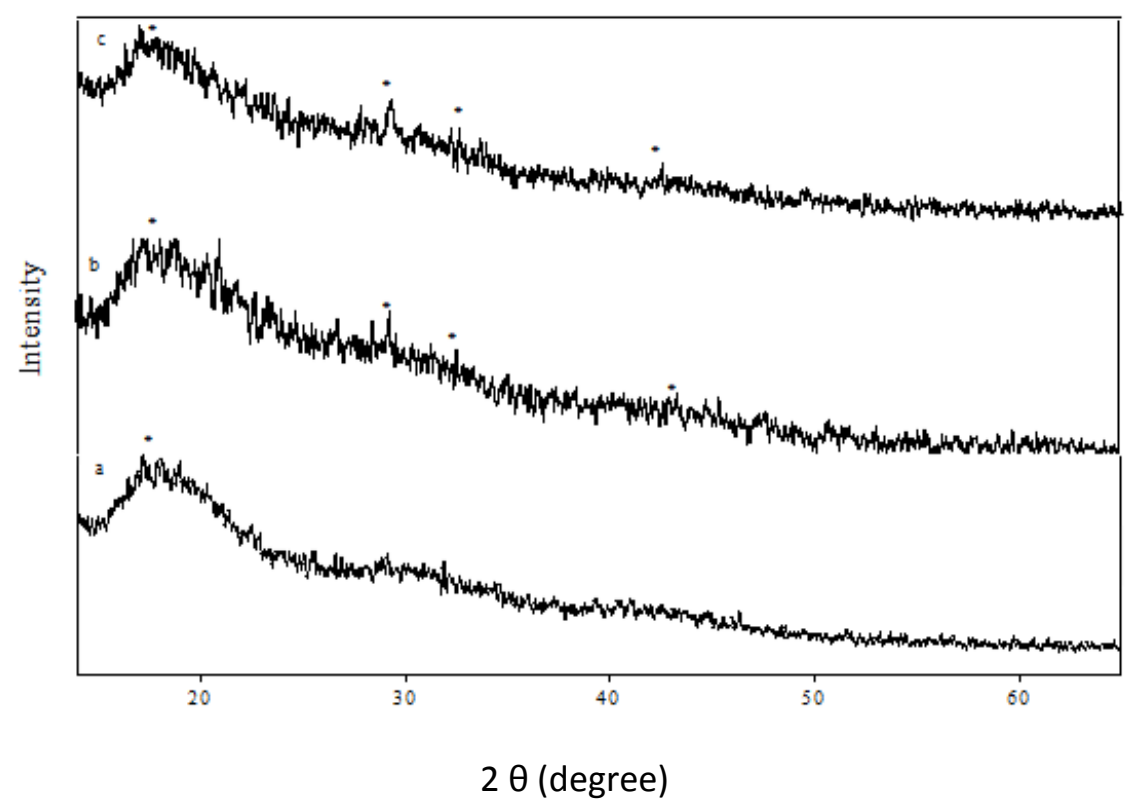

Fig. (9): XRD diffraction patterns of (GA/HEMA) copolymer hydrogel of gelation percent (a) (96\%), $\left(\mathrm{GA} / \mathrm{HEMA}^{-}\left(\mathrm{Fe}_{3} \mathrm{O}_{4}\right)\right.$ nanocomposites of different concentration (b) $(0.4 \mathrm{wt} \%)$ and (c) $(1 \mathrm{wt} \%)$

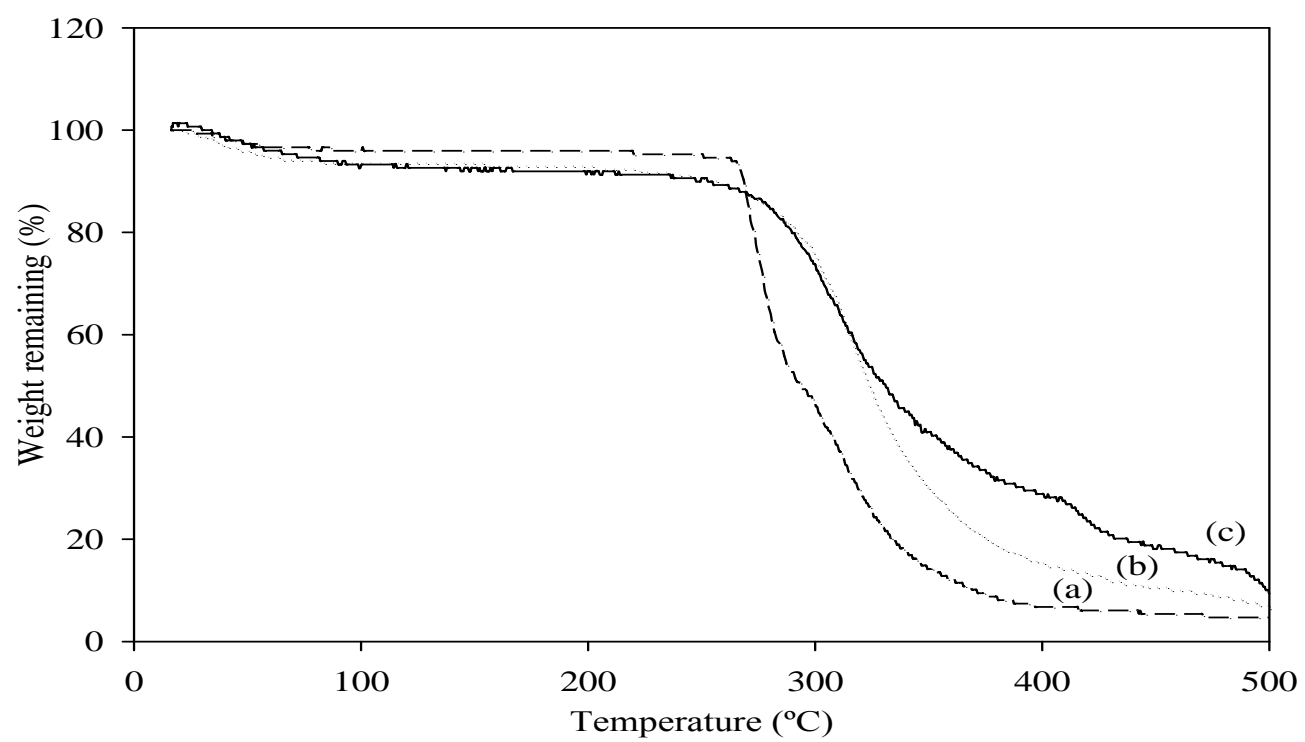

Fig. (10): TGA thermogram for (GA/HEMA) copolymer hydrogel of gelation percent (a) (96\%), $(\mathrm{GA} / \mathrm{HEMA})-\left(\mathrm{Fe}_{3} \mathrm{O}_{4}\right)$ nanocomposites of concentration (b) $(0.4 \mathrm{wt} \%)$ and (c) $(1 \mathrm{wt} \%)$
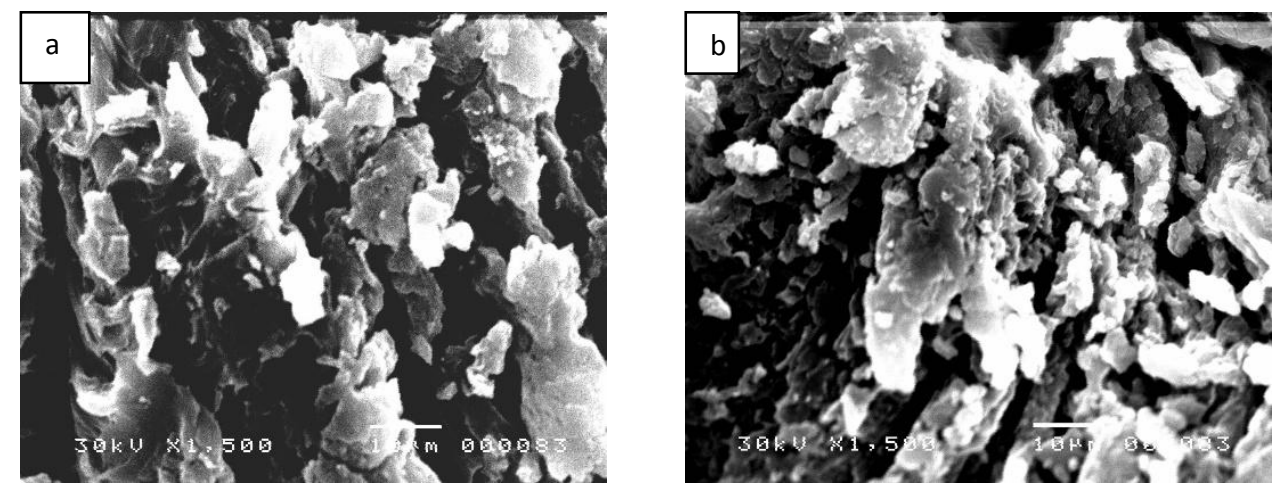

Fig. (11): SEM micrographs of (a) (GA/HEMA) copolymer hydrogel of gelation percent (96\%) and (b) (GA/HEMA)-( $\left.\mathrm{Fe}_{3} \mathrm{O}_{4}\right)$ nanocomposite of concentration (0.4wt\%). 

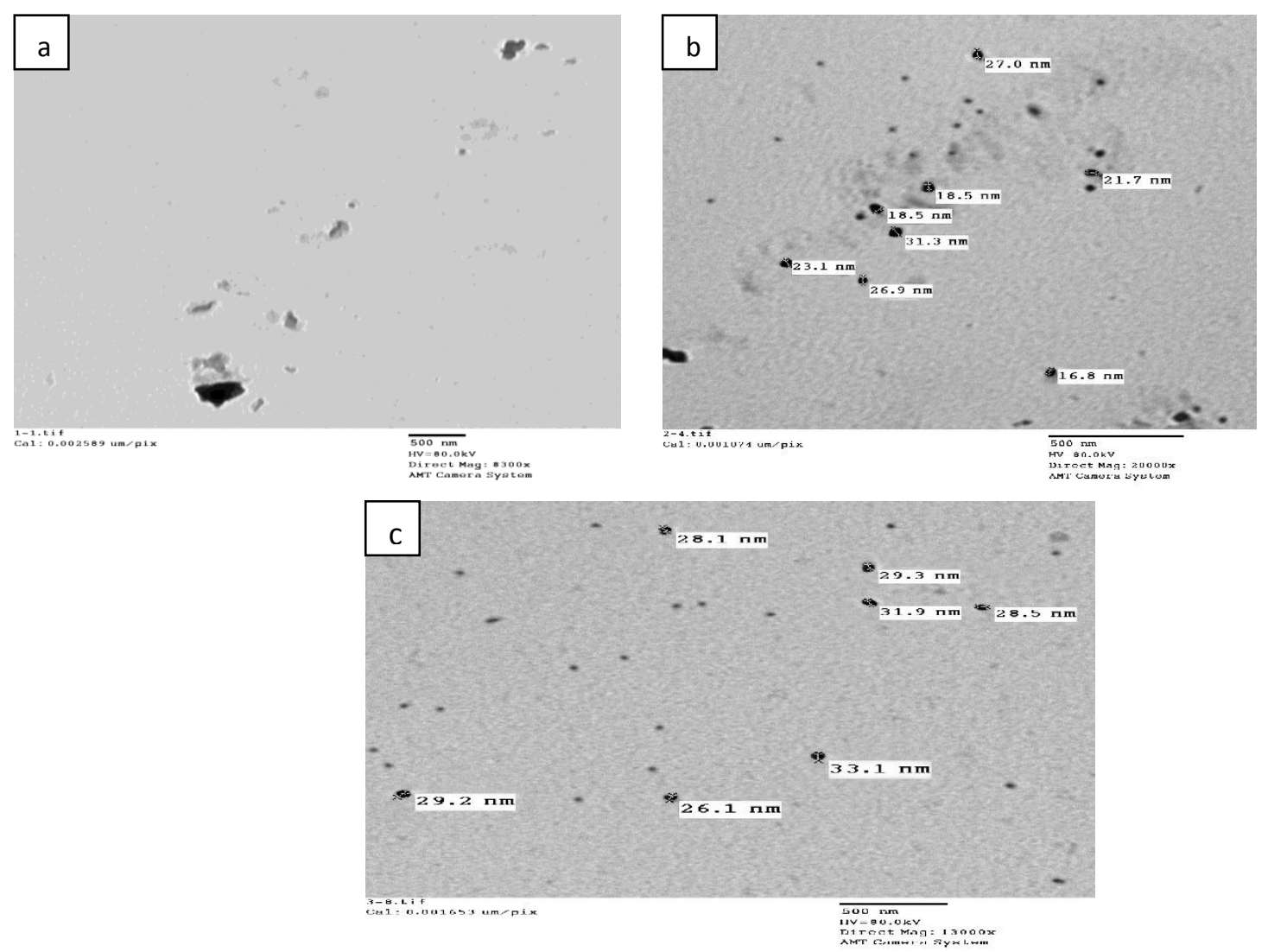

Fig. (12): TEM image of (a) (GA/HEMA) copolymer hydrogel of gelation percent (96\%), (b) $\left(\mathrm{GA} / \mathrm{HEMA}-\left(\mathrm{Fe}_{3} \mathrm{O}_{4}\right)\right.$ nanocomposites of concentration $(0.4 \mathrm{wt} \%)$ and $(\mathrm{c})(1 \mathrm{wt} \%)$

\section{Energy-dispersive x-ray (EDX) analysis}

Energy dispersive X-rays (EDX) analyses were carried out to determine the identity of the nanoparticle. (EDX) was used to analyze the elemental constituents of (GA/HEMA) copolymer hydrogel and (GA/HEMA)- $\left(\mathrm{Fe}_{3} \mathrm{O}_{4}\right)$ nanocomposites. Figure 13 (a) illustrates the EDX spectrum of (GA/HEMA) copolymer hydrogel of (96\%) gelation. EDX analysis verifies the absence of any peak in the region of both iron and oxygen range in the pristine hydrogel. In Fig 13(b), the existence of elemental iron $(\mathrm{Fe})$ and oxygen $(\mathrm{O})$ was detected by EDX, confirmed the formation of $\left(\mathrm{Fe}_{3} \mathrm{O}_{4}\right)$. The analysis confirmed the presence of iron oxide within the polymer matrix of (GA/HEMA).

\section{Vibrating sample magnetometer (VSM)}

The magnetic properties of (GA/HEMA)- $\left(\mathrm{Fe}_{3} \mathrm{O}_{4}\right)$ nanocomposites of concentration $(0.4 \mathrm{wt} \%)$ were tested and shown in Fig. (14). The magnetization $(M \mathrm{~s})$ and the retentivity of (GA/HEMA)- $\left(\mathrm{Fe}_{3} \mathrm{O}_{4}\right)$ nanocomposites were $0.58386 \mathrm{emu} / \mathrm{g}$ and $28.446 \mathrm{E}-$ $3 \mathrm{emu} / \mathrm{g}$, respectively which is much smaller than that of pure magnetite nanoparticles [42]. There have been several reports on the decrease in $M s$ values of composites as $\left(\mathrm{Fe}_{3} \mathrm{O}_{4}\right)$ nanoparticles are incorporated into a nonmagnetic polymer matrix, walls of polymer matrix act as a shield for magnetic power of nano $\mathrm{Fe}_{3} \mathrm{O}_{4}[43,44]$. Also, the reduction in the saturation magnetization can be attributed to a low percent of $\mathrm{Fe}_{3} \mathrm{O}_{4}$ in the nanocomposites. The result shows that no coercive force was found in the hysteresis curve, which demonstrated that the prepared (GA/HEMA)$\left(\mathrm{Fe}_{3} \mathrm{O}_{4}\right)$ nanocomposites had excellent superparamagnetism. The reason for superparamagnetic nature of the nanoparticles is due to the very small size of incorporated iron oxide particles which favors the redispersion of magnetic nanoparticles after the external magnetic field is removed [10].

Endoxan loading of (GA/HEMA) copolymer hydrogels and its magnetic nanocomposites

The total amount of endoxan adsorbed into dry hydrogels and dry nanocomposites at different initial concentrations of the drug are shown in Fig. (15). It can be noted that, the amount of total 
endoxan absorbed by the copolymer hydrogels and its nanocomposite increases with increasing the initial concentration of endoxan due to the specific interaction between the hydrogels and its nanocomposite with the drug molecule, interactions between positively charged drug to partially ionized hydrogels and its nanocomposite and also, to the higher frees volume available for diffusion. In other words, the diffusion of the drug inside the hydrogels matrix increases with increasing drug concentration [45]. It can also be seen that $(\mathrm{GA} / \mathrm{HEMA})-\left(\mathrm{Fe}_{3} \mathrm{O}_{4}\right)$ nanocomposites have the ability to load higher concentration than (GA/HEMA) copolymer hydrogel. This is due to the existence of a greater amount of free space between the hydrogel networks because nanoparticles formation, as well as the endoxan molecules, can also bind onto the surface of the nanoparticles [30, 38].

It also depends on the amount of GA existing in the hydrogel system: Amply, the increase of functional groups (carboxylic group) in GA loads a number of drug molecules, indicating that the polymer layer present on NPs plays an important role in loading endoxan molecules. This result illustrates the different uses of NPs as efficient vehicles for targeted delivery of anticancer therapeutic agents through conjunction with targeting molecules [30]. It was found that the optimum initial concentration that used in the in vitro release, get nearly a loaded amount of 36 $\mathrm{mg} / \mathrm{g}$ for GA/HEMA copolymer hydrogel and 50 $\mathrm{mg} / \mathrm{g}$ for nanocomposites and was used in vitro drug release study.

\section{In vitro release of endoxan drug}

The in vitro release experiments of dried-loaded hydrogel and loaded nanocomposite were carried out in Simulated Intestinal Fluid (SIF) which is almost similar to that of the intestine medium. Figure (16) shows the drug release study of (GA/HEMA) copolymer hydrogels and its nanocomposite as a function of time at $\mathrm{pH} 7.4$ and $37^{\circ} \mathrm{C}$. It is noted that the release of the endoxan drug increases with time until reaching the optimum releasing percent through $210 \mathrm{~min}$ for (GA/HEMA) copolymer hydrogel and nanocomposite. The optimum endoxan released was $58 \%(21 \mathrm{mg} / \mathrm{g})$ for (GA/HEMA) copolymer hydrogels and $97 \%(48.5 \mathrm{mg} / \mathrm{g})$ for nanocomposite. Endoxan release tests showed that nanocomposite has a higher release than copolymer hydrogels. This is due to the existing free space between the nanoparticles which allow to drug molecules entering into the medium and also due to embedding of $\mathrm{Fe}_{3} \mathrm{O}_{4}$ nanoparticles into the network which increases the surface area [38]. It is well known that the delivery of drugs from the hydrogels system can be controlled by external stimuli (in this case, an external magnetic field). The endoxan release from magnetic nanocomposite was found to be in a sustained manner Fig. (16). Since endoxan is a hydrophobic molecule, low amounts are entrapped in copolymer hydrogels. Therefore, these gels show a sustained drug release profiles. But, by employing an external applied magnetic field such as magnetite has improved the delivery of endoxan from magnetic nanocomposite into the medium [38]. An improved release obtained in nanocomposite is caused by the alignment of magnetic nanoparticles by the external magnetic field which in turn expands the hydrogels networks that allow more number of endoxan molecules to release into the medium [30, 46]; therefore, the diffusion and liberation of endoxan throughout the polymer matrix increased. The release obtained data indicated that (GA/HEMA)- $\left(\mathrm{Fe}_{3} \mathrm{O}_{4}\right)$ nanocomposites can be used for localized drug delivery for the endoxan drug in a neutral environment of the intestine.

\section{Conclusion}

In this study, (GA/HEMA) copolymer hydrogel and (GA/HEMA)-( $\left(\mathrm{Fe}_{3} \mathrm{O}_{4}\right)$ magnetic nanocomposite were prepared by gamma irradiation as an initiator. Magnetite $\left(\mathrm{Fe}_{3} \mathrm{O}_{4}\right)$ has been prepared by chemical co-precipitation technique. The crosslinked chemical structure of (GA/HEMA) copolymer hydrogel and (GA/HEMA)- $\left(\mathrm{Fe}_{3} \mathrm{O}_{4}\right)$ magnetic nanocomposite have been confirmed by Fourier transform infrared spectroscopy (FTIR). XRD and TEM confirmed the incorporation of $(\mathrm{Fe})$ nanoparticles in (GA/HEMA) matrix. The swelling of copolymer hydrogel and its nanocomposites were affected by $\mathrm{pH}$. (GA/HEMA)- $\left(\mathrm{Fe}_{3} \mathrm{O}_{4}\right)$ nanocomposites have higher swelling percent than that of (GA/HEMA) copolymer hydrogel and both reached the maximum swelling percent at $6 \mathrm{~h}$. The optimum endoxan drug released was $58 \%$ for (GA/HEMA) copolymer hydrogels and $97 \%$ for nanocomposite during $210 \mathrm{~min}$. The prepared (GA/HEMA)$\left(\mathrm{Fe}_{3} \mathrm{O}_{4}\right)$ nanocomposite could be used for localized drug delivery for the endoxan drug in a neutral environment of the intestine. 

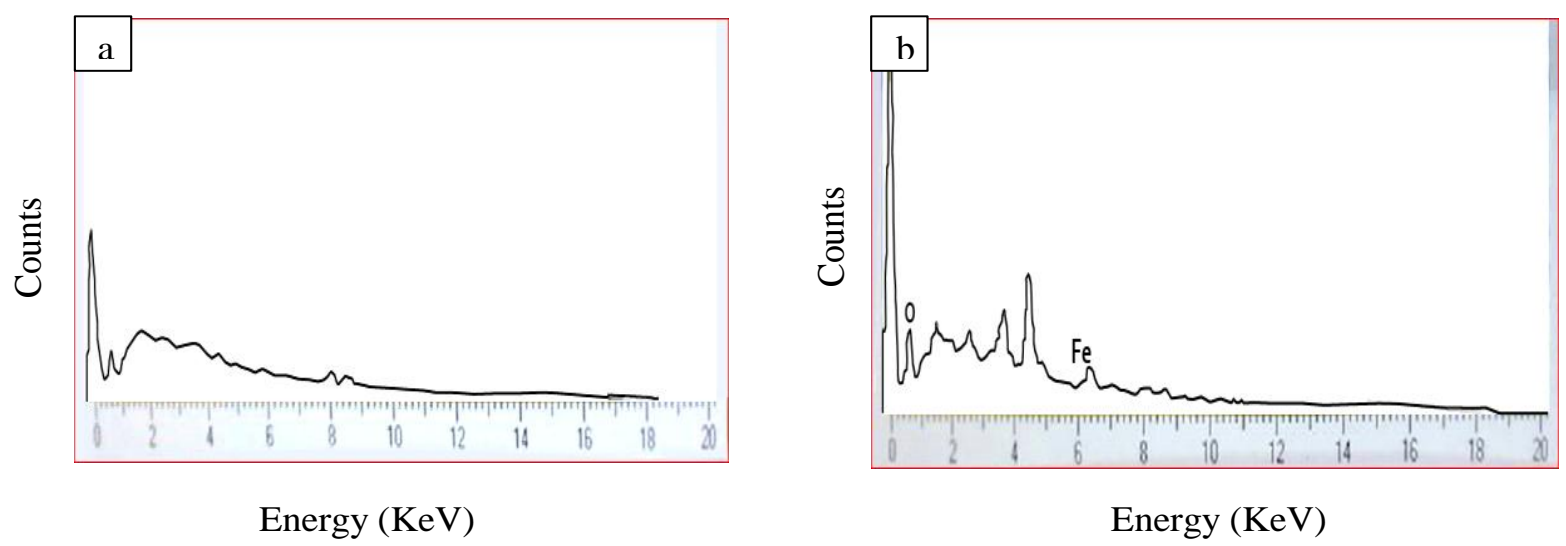

Fig. (13): EDX spectra of (a) (GA/HEMA) copolymer hydrogel of gelation percent $(96 \%)$ and (b) $(\mathrm{GA} / \mathrm{HEMA})-\left(\mathrm{Fe}_{3} \mathrm{O}_{4}\right)$ nanocomposite of concentration $(0.4 \mathrm{wt} \%)$

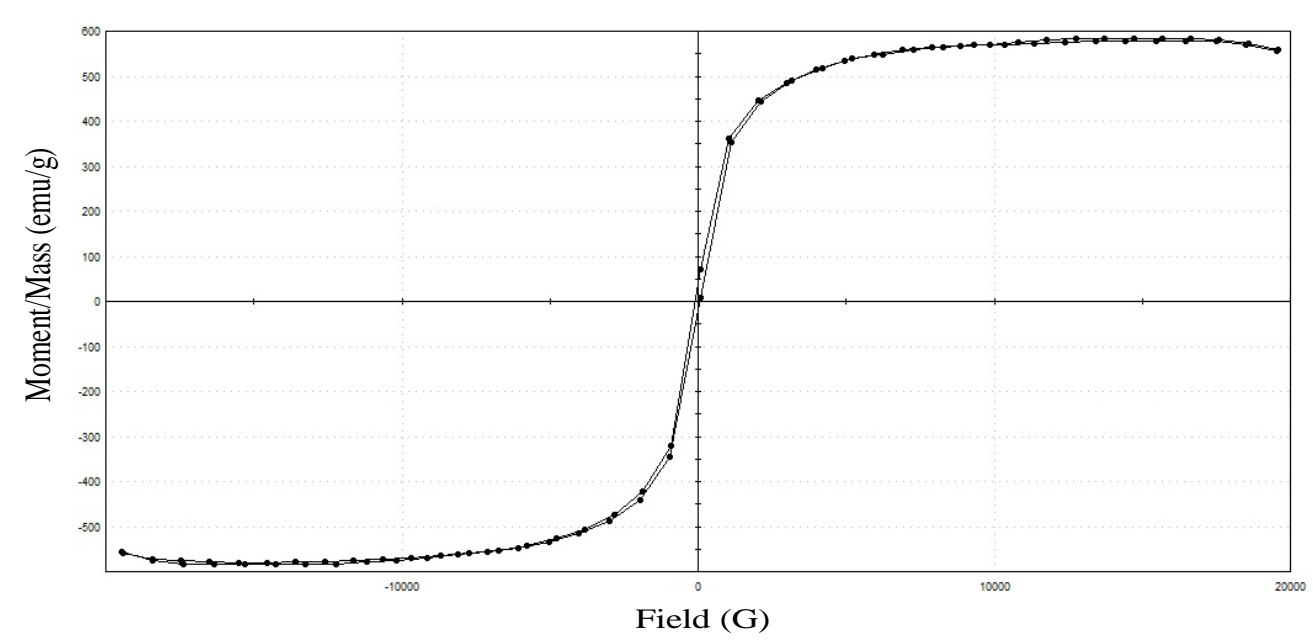

Fig. (14): VSM curve of (GA/HEMA)-( $\left.\mathrm{Fe}_{3} \mathrm{O}_{4}\right)$ nanocomposites of concentration $(0.4 \mathrm{wt} \%)$.

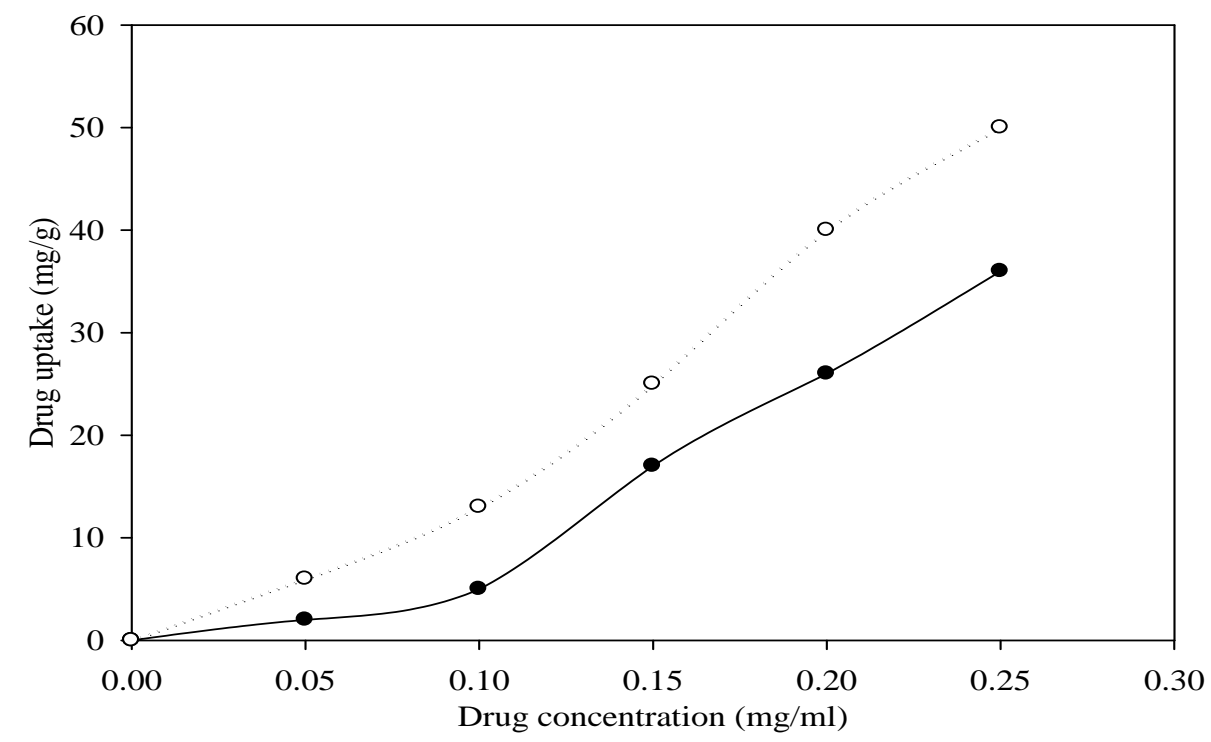

Fig. (15): Endoxan drug uptake by $(\bullet)$ (GA/HEMA) copolymer hydrogel and (०) (GA/HEMA)-( $\left.\mathrm{Fe}_{3} \mathrm{O}_{4}\right)$ nanocomposite at $37^{\circ} \mathrm{C}, \mathrm{PH} 7.4$ and different endoxan concentrations 


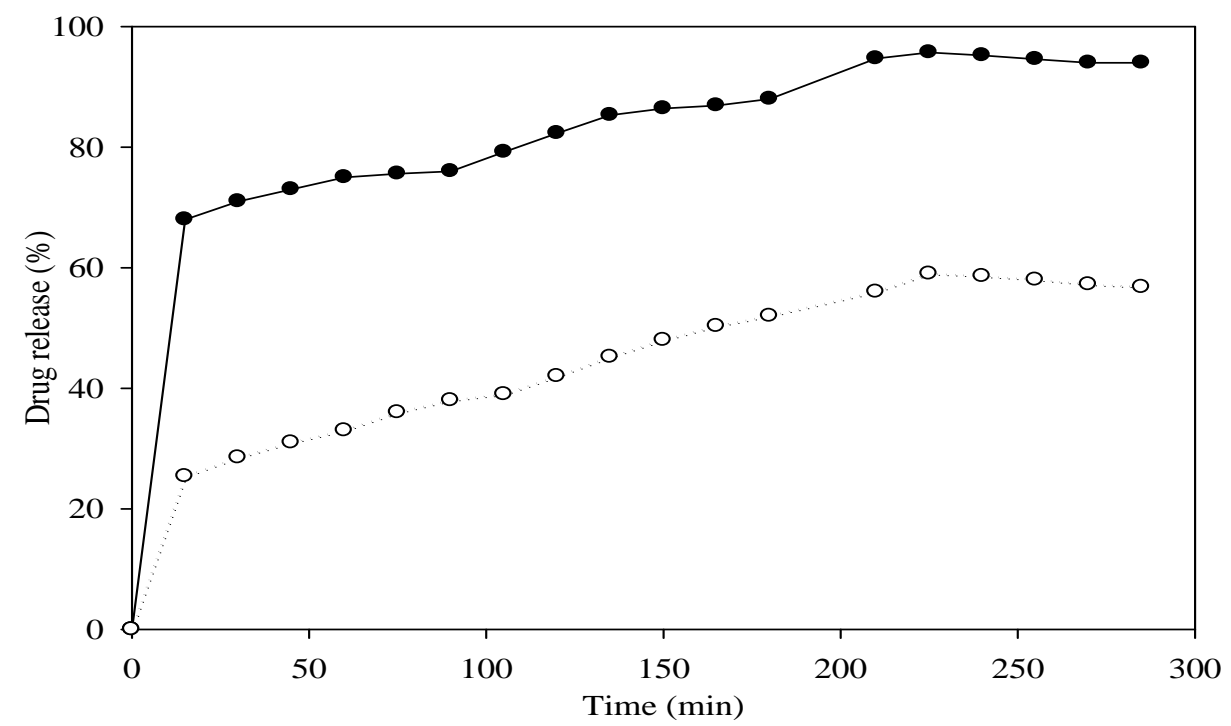

Fig (16): Endoxan drug release from (०) (GA/HEMA) copolymer hydrogels and (•) (GA/HEMA)-( $\left.\mathrm{Fe}_{3} \mathrm{O}_{4}\right)$ nanocomposite at $37^{\circ} \mathrm{C}$, PH 7.4

\section{References}

[1] Gao, J., Gu, H. and Xu, B. (2009). Multifunctional magnetic nanoparticles: design, synthesis, and biomedical applications. Accounts of chemical research 42(8): 1097-1107.

[2] Muller, R.H. and Keck, C. M. (2004). Challenges and solutions for the delivery of biotech drugs-a review of drug nanocrystal technology and lipid nanoparticles. Journal of Biotechnology 113(1-3): 151-170.

[3] Ding, P., Huang, K.L. and Liu, Y.F. (2007). Preparation and properties of modified chitosan as potential matrix materials for drug sustainedrelease beads. International journal of biological macromolecules 41(2): 125-131.

[4] Kálal, J. (1984). The use of methacrylic polymers in medicine. Macromolecular Chemistry and Physics 7(S19841): 31-39.

[5] Tomić, S. L., Suljovrujić, E.H. and Filipović, J.M. (2006). Biocompatible and bioadhesive hydrogels based on 2-hydroxyethyl methacrylate, monofunctional poly (alkylene glycol) s and itaconic acid. Polymer Bulletin 57(5): 691-702.

[6] Dafader, N.C., Adnan, M.N., Haque, M.E., Huq, D. and Akhtar, F. (2011). Study on the properties of copolymer hydrogel obtained from acrylamide/2hydroxyethyl methacrylate by the application of gamma radiation. African Journal of Pure and Applied Chemistry 5(5): 111-118.

[7] Nishi, K., Antony, M., and Jayakrishnan, A. (2007). Synthesis and evaluation of ampicillin conjugated gum arabic microspheres for sustained release. Journal of pharmacy and pharmacology 59(4): 485-493.

[8] Banerjee, S.S. and Chen, D.H. (2008). Cyclodextrin conjugated magnetic colloidal nanoparticles as a nanocarrier for targeted anticancer drug delivery. Nanotechnology 19(26): 265602.

[9] Zhang, X., LI, X. and Jiang, B. (2006). Preparation and Characterization of Nanometer Magnetite. Chemical Industry and Engineering 1: 45-48.

[10] Gupta, M.K., Bajpai, J. and Bajpai, A.K. (2014). Preparation and characterizations of superparamagnetic iron oxide embedded poly (2hydroxyethyl methacrylate) nanocarriers. Journal of Applied Polymer Science 131(18).

[11] Mahmoud, G.A. and Hegazy, D.E.A. (2014). Radiation Synthesis and Characterization of Polystyrene/Methacrylic Acid Microcomposite for Drug Delivery uses. Arab Journal of Nuclear Sciences and Applications 47(2): 54-67.

[12] Park, S.E., Nho, Y.C., Lim, Y.M., Kim, H. (2004). Preparation of $\mathrm{pH}$-sensitive poly(vinyl alcohol-g-methacrylic acid) and poly(vinyl alcohol-g-acrylic acid) hydrogels by gamma-ray irradiation and their insulin release behavior. Journal of Applied Polymer Science 91: 636-643

[13] Asem, H. (2016). Synthesis of Polymeric Nanocomposites for Drug Delivery and Bioimaging, KTH Royal Institute of Technology. 
[14] Hua, R. and Li, Z. (2014). Sulfhydryl functionalized hydrogel with magnetism: Synthesis, characterization, and adsorption behavior study for heavy metal removal. Chemical Engineering Journal 249: 189-200.

[15] El-Nesr, E.M., Raafat, A.I., Nasef., S.M., Soliman., E.A. and Hegazy, E.A. (2014). Radiation synthesis and characterization of $\mathrm{N}, \mathrm{O}$-carboxymethyl chitosan/poly (vinylpyrrolidone) Copolymer Hydrogel. Arab Journal of Nuclear Science and Applications, 47(1), 14-27.

[16] Ali, A. E.-H., Shawky, H.A., El-Sayed, M.H., and Ibrahim. H. (2008). Radiation synthesis of functionalized polypropylene fibers and their application in the treatment of some water resources in the western desert of Egypt. Separation and Purification Technology 63(1): 6976.

[17] Ibrahim, M.S., Ibrahim, S.M. and Farag, S.A. (2007). Characterization, thermal, and mechanical behaviors of gamma-irradiated gum arabic/polyvinyl alcohol polymer blends. PolymerPlastics Technology and Engineering 46(12): 1143-1149.

[18] El-Mohdy, H.A., Hegazy, E.A. and El-Nesr, E.M. (2013). Metal sorption behavior of poly ( $\mathrm{N}$-vinyl2-pyrrolidone)/(acrylic acid-co-styrene) hydrogels synthesized by gamma radiation. Journal of Environmental Chemical Engineering 1(3): 328338.

[19] Wang, M., Xu, L., Hu, H., Zhai, M., Peng, J., Nho, Y., Li, J., and Wei, G. (2007). Radiation synthesis of PVP/CMC hydrogels as a wound dressing. Nuclear Instruments and Methods in Physics Research Section B: Beam Interactions with Materials and Atoms 265(1): 385-389.

[20] Jovanović, Ž., Krklješ, A., Stojkovska, J., Tomic, S., Obradovic, B., Stankovic, V.M. and Popovic, Z.K. (2011). Synthesis and characterization of silver/poly (N-vinyl-2-pyrrolidone) hydrogel nanocomposite obtained by in situ radiolytic methods. Radiation Physics and Chemistry 80(11): 1208-1215.

[21] Varshney, L. (2007). Role of natural polysaccharides in radiation formation of PVAhydrogel wound dressing. Nuclear Instruments and Methods in Physics Research Section B: Beam Interactions with Materials and Atoms 255(2): 343-349.

[22] Chang, P.R., Yu, J., Ma, X. and Anderson, D.P. (2011). Polysaccharides as stabilizers for the synthesis of magnetic nanoparticles. Carbohydrate polymers $83(2)$ : 640-644.
[23] Dostelek, J. and Johas, U. (2012). Nanoengineered hydrogel template for synthesis of silver nanoparticles. Advanced Engineering and Applied Sciences: An International Journal 1(1): 5-10.

[24] Soleimani, F. and Sadeghi, M. (2012). Synthesis of $\mathrm{pH}$-sensitive hydrogel based on starchpolyacrylate superabsorbent. Journal of Biomaterials and Nanobiotechnology 3(2A): 310.

[25] Mohan, Y.M., Vimala, K., Thomas, V., Varaprasad, K., Sreedhar, B., Bajpai, S.K. and Raju, K.M. (2010). Controlling of silver nanoparticles structure by hydrogel networks. Journal of Colloid and Interface Science 342(1): 73-82.

[26] Yang, J. M., Su, W.Y., Leu, T.L. and Yang, M.C. (2004). Evaluation of chitosan/PVA blended hydrogel membranes. journal of Membrane Science 236(1-2): 39-51.

[27] Gils, P.S., Ray, D., Mohanta, G.P., Manavalan, R., Ray, D. and Sahoo, P. (2009). Designing of new acrylic-based macroporous superabsorbent polymer hydrogel and its suitability for drug delivery. International Journal of Pharmacy and Pharmaceutical Sciences 1: 43-54.

[28] Ramos, J.M., Versiane, O., Felcman, J. and Soto, C.T. (2007). Fourier transform infrared spectrum, vibrational analysis and structural determinations of the trans-bis (glycine) nickel (II) complex by means of the RHF/6-311G and DFT: B3LYP/6$31 \mathrm{G}$ and 6-311G methods. Spectrochimica Acta Part A: Molecular and Biomolecular Spectroscopy 68(5): 1370-1378.

[29] Sivudu, K.S. and Rhee, K.Y. (2009). Preparation and characterization of $\mathrm{pH}$-responsive hydrogel magnetite nanocomposite. Colloids and Surfaces A: Physicochemical and Engineering Aspects 349(1-3): 29-34.

[30] Manjula, B., Veerapratap, S., Sadiku, R. and Raju, K.M. (2017). Development of Magnetic NanoParticles Embedded in Hydrogels Based on Sodium Alginate and Gelatin for Biomedical Application. International Journal of Pharmacy and Pharmaceutical Research 8(4): 92-106.

[31] Zhu, C. H., Lu, Y., Chen, J.F. and Yu, S.H. (2014). Photothermal Poly (N-isopropylacrylamide)/Fe3O4 Nanocomposite Hydrogel as a Movable Position Heating Source under Remote Control. Small 10(14): 2796-2800.

[32] Almuslet, N.A., Hassan, E.A., Al-Sherbini, A. and Muhgoub, M.G. (2012). Diode laser (532 nm) induced grafting of polyacrylamide onto Gum Arabic. Journal of Physical Science 23(2): 43-53. [33] El-Din, T. S., Elzatahry, A.A., Aldhayan, 
D.M., Al - Enizi, A.M. and Al - Deyab, S.S. (2011). "Synthesis and characterization of magnetite zeolite nanocomposite." International Journal of Electrochemical Science. 6: 6177-6183.

[33] El-Din, T. S., Elzatahry, A. A., Aldhayan, D. M., Al-Enizi, A. M. and Al-Deyab, S.S. (2011). Synthesis and characterization of magnetite zeolite nanocomposite. International Journal of Electrochemical Science 6: 6177-6183.

[34] Zohuriaan, M.J. and Shokrolahi, F. (2004). Thermal studies on natural and modified gums. Polymer Testing 23(5): 575-579.

[35] Juby, K..A., Dwivedi, C., Kumar, M., Kota, S., Misra, H.S. and Bajaj, P.N. (2012). Silver nanoparticle-loaded PVA/gum acacia hydrogel: Synthesis, characterization and antibacterial study. Carbohydrate polymers 89(3): 906-913.

[36] Liu, S., Zhang, L., Zhou, J., Xiang, J., Sun, J. and Guan, J. (2008). Fiberlike $\mathrm{Fe}_{2} \mathrm{O}_{3}$ macroporous nanomaterials fabricated by calcinating regenerate cellulose composite fibers." Chemistry of Materials 20(11): 3623-3628.

[37] Sadegh, H., Ghoshekandi, R.S. and Kazemi, M. (2014). The study in synthesis and characterization of carbon nanotubes decorated by magnetic iron oxide nanoparticles. International Nano Letters 4(4): 129-135.

[38] Reddy, N. N., Mohan, Y.M., Varaprasad, K., Ravindra, S., Joy, P.A. and Raju, K.M. (2011). Magnetic and electric responsive hydrogelmagnetic nanocomposites for the drug-delivery application. Journal of Applied Polymer Science 122(2): 1364-1375.

[39] Govindan, S., Nivethaa, E.A.K., Saravanan, R., Narayanan, V. and Stephen, A. (2012). Synthesis and characterization of the chitosan-silver nanocomposite. Applied Nanoscience 2(3): 299303.

[40] El-Arnaoutya, M.B., Eid, M., Sallam, O.I. and Mostafa, A.B. (2015). Effective Removal of Copper Ions and Dyes from Aqueous Solutions by
Polymeric Nanoparticles Prepared by Gamma Radiation. Arab Journal of Nuclear Sciences and Applications 48(1): 10-23.

[41] Eid, M. (2011). Gamma radiation synthesis and characterization of starch-based polyelectrolyte hydrogels loaded silver nanoparticles. Journal of Inorganic and Organometallic Polymers and Materials 21(2): 297-305.

[42] Yuanbi, Z., Zumin, Q. and Huang, J. (2008). Preparation and analysis of $\mathrm{Fe} 3 \mathrm{O} 4$ magnetic nanoparticles used as targeted-drug carriers. Chinese Journal of Chemical Engineering 16(3): 451-455.

[43] Bhatt, A. S., Bhat, D.K. and Santosh, M.S. (2010). Electrical and magnetic properties of chitosanmagnetite nanocomposites. Physica B: Condensed Matter 405(8): 2078-2082.

[44] Park, J.Y., Patel, D., Choi, E.S., Baek, M.J., Chang, Y., Kim, T.J. and Lee, G.H. (2010). Salt effects on the physical properties of magnetite nanoparticles synthesized at different $\mathrm{NaCl}$ concentrations. Colloids and Surfaces A: Physicochemical and Engineering Aspects 367(13): 41-46.

[45] El-Arnaouty, M.B. (2010). Effect of mono and diprotic acid on the characterization of 2hydroxyethyl-methacrylate based hydrogels prepared by $\gamma$-radiation and its application for delivery. Journal of Radiation Research and Applied Sciences. 3: 763-790.

[46] Wang, Q., Xie, X., Zhang, X., Zhang, J. and Wang, A. (2010). Preparation and swelling properties of $\mathrm{pH}$-sensitive composite hydrogel beads based on chitosan-g-poly (acrylic acid)/vermiculite and sodium alginate for diclofenac controlled release. International journal of biological macromolecules 46(3): 356-362. 